\title{
Studies on the Stability of Corticosteroids: Degradation of Clobetasol Propionate, Desonide and Hydrocortisone in Topical Formulations by HPLC and UPLC-MS/MS
}

\author{
Kishore Kumar Hotha ${ }^{1 *}$, Subathra Ramamoorthy ${ }^{1}$, Hiren Patel ${ }^{2}$ \\ ${ }^{1}$ Analytical Research \& Development, LUPIN SOMERSET, Somerset, NJ, USA \\ ${ }^{2}$ Product Development, LUPIN SOMERSET, Somerset, NJ, USA \\ Email: *drhotha@gmail.com, ${ }^{\star}$ kishorehotha@lupin.com
}

How to cite this paper: Hotha, K.K., Ramamoorthy, S. and Patel, H. (2020) Studies on the Stability of Corticosteroids: Degradation of Clobetasol Propionate, Desonide and Hydrocortisone in Topical Formulations by HPLC and UPLC-MS/MS. American Journal of Analytical Chemistry, 11, 147-171.

https://doi.org/10.4236/ajac.2020.114012

Received: February 28, 2020

Accepted: March 29, 2020

Published: April 1, 2020

Copyright (C) 2020 by author(s) and Scientific Research Publishing Inc. This work is licensed under the Creative Commons Attribution International License (CC BY 4.0).

http://creativecommons.org/licenses/by/4.0/

\section{(c) (i) Open Access}

\begin{abstract}
Corticosteroids are the most widely used class of anti-inflammatory medications in the pharmaceutical industry. There are several pharmaceutical dosage forms available using different corticosteroids. Topical steroids of varying potencies are available in creams, ointments, solutions and other vehicles. Chemical instability and drug degradation are the key quality concerns for these topical dosage forms. Nature of the dosage forms, excipient quality, product composition, and process optimization are some of the common factors which affect the stability of corticosteroids. This article describes drug degradation behavior of three different corticosteroids in different topical dosage forms. Drug degradation patterns of Hydrocortisone, Clobetasol propionate and Desonide formulations observed in stability studies of respective finished drug products under ICH recommended storage conditions were investigated. HPLC, UPLC-MS/MS methods were developed for the separation and characterization of impurities. The structural elucidation of the unknown impurities observed for these steroids and mechanistic consideration of potential degradation pathways has been discussed. Detailed discussion on the analytical methodologies is included as well.
\end{abstract}

\section{Keywords}

Topical Steroids, Chemical Degradation, Clobetasol Propionate, Desonide, Hydrocortisone, Steroids, UPLC-MS/MS

\section{Introduction}

Corticosteroids (Figure 1) containing the 1,3-dihydroxyacetone side chain on 
their D-rings, such as Betamethasone, Dexamethasone, Hydrocortisone, Clobetasol propionate and related compounds are an important class of organic compounds arranged in typical configuration. They are widely used as potent anti-inflammatory and immunomodulatory agents and formulated in several dosage forms (Figure 1) [1] [2] [3] [4]. Based on the formulation composition, excipient, $\mathrm{pH}$ and thermal stability, the degradation of corticosteroids in varied formulations can be induced via different mechanisms [5] [6] [7] [8].

There were several articles reported for the corticosteroids degradation by various analytical techniques [5]-[13]. Enol aldehyde via $\beta$-elimination, mattox rearrangement, Bayer villager oxidation are some of the known mechanisms for these degradation pathways. There were several impurities can be formed based on the formulation composition, excipient, $\mathrm{pH}$ and thermal stability. In the current article steroids Hydrocortisone, Clobetasol propionate and Desonide formulations were evaluated in the finished product dosage forms and impurity profiling by UPLC-MS/MS was performed. Many authors proposed methods based on gas chromatography/mass spectrometry for the detection of corticosteroids [9] [14]-[26].

Hydrocortisone (Figure 2) is used in treating severe allergies, arthritis, asthma, multiple sclerosis, and skin conditions. There were several formulations associated with the Hydrocortisone in terms of creams, ointments and otic solution. Hydrocortisone-Acetic acid otic solution is used to treat certain problems of the ear canal. There were several analytical methods that were developed for the Hydrocortisone estimation in creams and lotion dosage forms. Several articles are available about the degradation pathways of hydrocortisone in suspensions as well as in microbial environments [6] [9] [26] [27]. The current research article thoroughly reviewed about the degradation mechanism of the Hydrocortisone in the Hydrocortisone acetic acid otic solution in the stability conditions. During the analysis of the stability samples, two unknown peaks were identified and characterized. One unknown peak is the keto impurity of the Hydrocortisone which is a

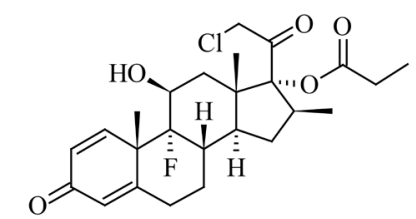

Clobetasol Propionate Monoisotopic Mass: 466.1Da<smiles>CC12CCC(=O)C=C1CC[C@H]1[C@@H]2C(O)CC2(C)[C@@H]1CC[C@@]2(O)C(=O)CO</smiles>

Hydrocortisone

Monoisotopic Mass: 362.2Da

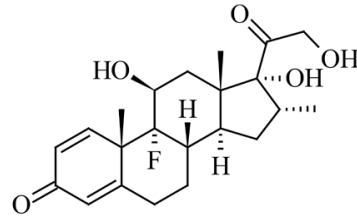

Dexamethasone Monoisotopic Mass: 392.1Da

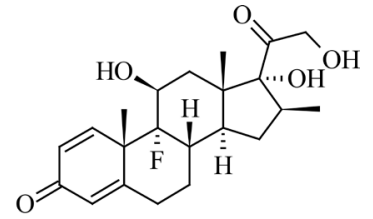

Betamethasone Monoisotopic Mass: 392.1Da

Figure 1. Chemical structures of corticosteroids. 

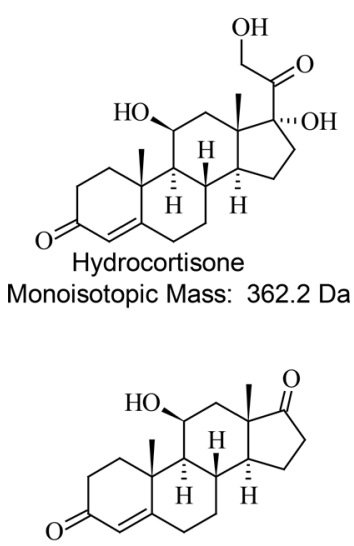

4-Androsten-11ß-ol-3,17-dione (Keto Impurity)

Monoisotopic Mass: 302.1 Da

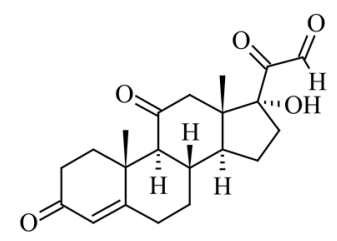

21 -Dehydro Hydrocortisone Monoisotopic Mass: 358.1 Da

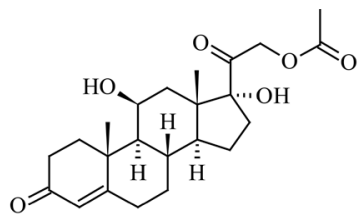

Hydrocortisone Acetate Monoisotopic Mass: 404.2 Da

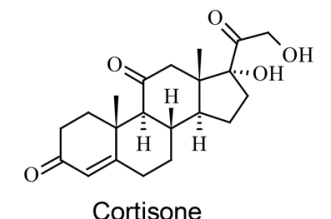

Monoisotopic Mass: 360.1Da<smiles>C[C@]12CCC(=O)C=C1CC[C@H]1[C@@H]2CC[C@@]1(OC(=O)O)C(=O)O</smiles>

17-formoxyl Impurity Monoisotopic Mass: $376.1 \mathrm{Da}$

Figure 2. Hydrocortisone impurities.

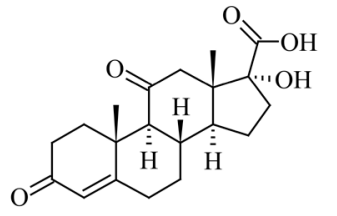

Hydrocortisone carboxylic acid Monoisotopic Mass: $346.1 \mathrm{Da}$

predominate oxidative degradant as well as metabolite of the many corticosteroids [3] [18] [19]. The second impurity was the 17-formoxyl impurity where it arises due to the Bayer villager oxidation of the aldehyde group. Structural elucidation was performed using LCMSMS and NMR.

Clobetasol propionate (Figure 3 ) is a class 1 corticosteroid and is a super high potency di-halogenated corticosteroid that has been commercially available since 1973. It was used in the treatment of skin conditions such as severe psoriasis, seborrheic dermatitis and extreme photo dermatitis in HIV/AIDS. There were articles described for the forced degradation of Clobetasol in bulk drug and cream formulations by HPLC [9] [17] [26] [28] [29] [30]. However there was no detailed degradation pathways of Clobetasol not been published to the best of our knowledge. In this article, degradation pathways of Clobetasol propionate evaluated in ointment, lotion and topical solution. During the stability of the topical solution unknown impurity was observed. UPLC-MS/MS and NMR performed for the Characterization of the unknown impurities in the stability samples of the Pharmaceutical Dosage forms.

Desonide (Figure 4) is a glucocorticoid with anti-inflammatory and antipruritic activities that is used in the treatment of corticosteroid-responsive dermatoses. These drugs are widely used for the treatment of skin diseases of inflammatory, proliferative, or immunological origin. In this article Desonide stability in the pharmaceutical dosage forms of ointment and lotion is discussed. During the stability sample analysis of Desonide lotion there was one unknown impurity observed which was characterized by UPLC-MS/MS analysis. 
<smiles>CCC(=O)OC12C(=O)C1(Cl)C1(C)CC(O)C3C(CCC4=CC(=O)C=CC43C)C1CC2C</smiles>

Clobetasol Propionate Monoisotopic Mass: 466.1Da

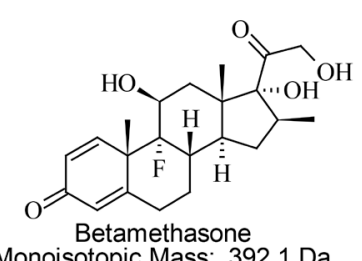
Monoisotopic Mass: $392.1 \mathrm{Da}$<smiles></smiles>
21 Dehydro 17 deoxy Betamethasone Monoisotopic Mass: 374.1 Da

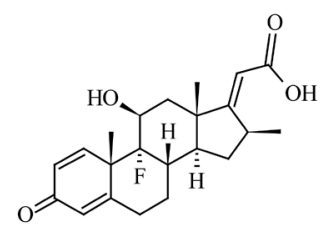

Clobetasol acetic acid Impurity Monoisotopic Mass: $374.1 \mathrm{Da}$

Figure 3. Clobetasol propionate impurities.<smiles>CC1(C)O[C@H]2C[C@@H]3[C@H](C(O)C[C@]2(C)[C@H]1C(=O)CO)[C@H]1[C@@H]3CCC2=CC(=O)C=C[C@@]21C</smiles>

Desonide Monoisotopic Mass: 416.2 Da<smiles>CC1C[C@H]2C3CCC4=CC(=O)C=CC4(C)C3C(O)CC2(C)C1(C(=O)Cl)C(=O)CCl</smiles>

Monoisotopic Mass: 410.1 Da
Clobetasol Related Compound A (3,3,20 dione Impurity) Monoisotopic Mass: 448.1Da

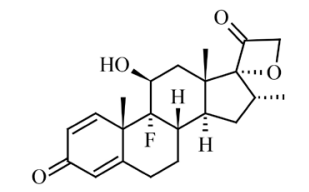

Dexamethasone oxetanone Monoisotopic Mass: $374.1 \mathrm{Da}$<smiles>CC1=C(C(=O)CCl)C2(C)CC(O)C(C)C2C2CC(C)C3(C)C=CC(=O)C=C3CCC12</smiles>

Clobetasol Related Compound B (Delta Chloro Impurity)

Monoisotopic Mass: $392.1 \mathrm{Da}$

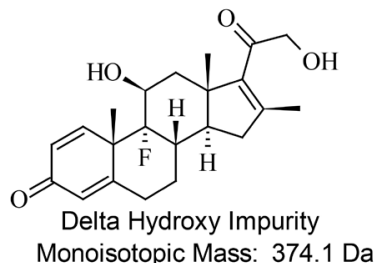<smiles>CC1CC(O)C2CC34C=CC(=O)C=C3CCC4C2CC1C</smiles>

Enol aldehyde Isomer Monoisotopic Mass: 374.1 Da

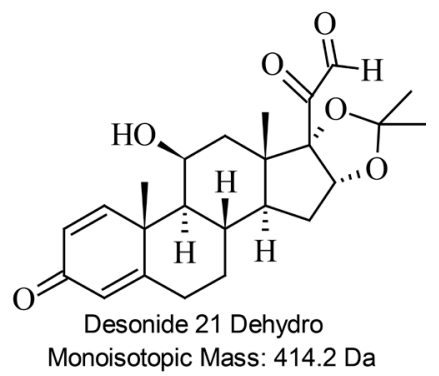

alpha hydroxy prednisolone Monoisotopic Mass: 376.19 Da

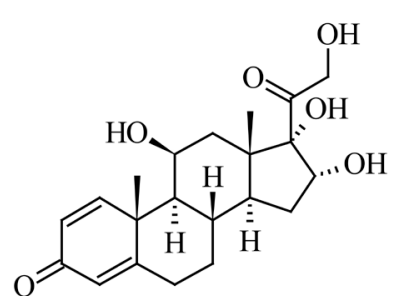$$
\mathrm{O}
$$ 


\section{Experimental}

\subsection{Chemical and Reagents}

Hydrocortisone working standard and impurity standards were supplied by Tianjin Jinjin Pharmaceutical Company, China whereas Clobetasol propionate, Desonide, Dexamethasone, Betamethasone were procured from Teva Pharmaceuticals and from sigma Aldrich, USA. The HPLC grade acetonitrile, methanol, and analytical grade ammonium formate, formic acid were purchased from Merck, Darmstadt, Germany. Water used was obtained by using Millipore MilliQ Plus water purification system. Drug product samples were supplied by Lupin Somerset, New Jersey.

\subsection{Equipment}

LC-MS/MS system (Acquity UPLC coupled with TQD mass spectrometer with empower software, HPLC with empower software Waters Corporation, Milford, USA) was used for the identification of unknown compounds formed during forced degradation and stability testing studies. Cintex digital water bath was used for hydrolysis studies. Thermal stability studies were performed in a dry air oven (Cintex, Mumbai, India).

\section{Chromatographic Conditions}

HPLC and UPLC-MS/MS analysis was performed for stability analysis and for the impurity identification. All the chromatographic conditions were described as follows.

\section{HPLC Chromatographic Conditions}

HPLC (PDA Detector with empower software, Waters Corporation, Milford, USA) was used for the analysis of finished product samples and forced degradation and stability testing studies for Hydrocortisone. The chromatographic column used was Luna C18 (2), 100A, $4.6 \times 250 \mathrm{~mm}, 5.0 \mu \mathrm{m}$ particle size, Manufacturer: Phenomenex. The separation was achieved on a gradient method. 0.05 $\mathrm{M}$ of potassium phosphate monobasic buffer adjusted to $\mathrm{pH} 4.5$ was used as a buffer and acetonitrile was used as a mobile phase B. The HPLC gradient program was set as Time (min)/\% solution B: 0.0/26, 18/26, 32/45, 48.00/70, 58/70, $60 / 26,75 / 26$. The column temperature was maintained at $40^{\circ} \mathrm{C}$ and the injection volume was $20 \mu \mathrm{L}$. Acetonitrile and a mixture of Milli-Q water in the proportion of 60:40 (v/v); respectively used as diluent. The mobile phase was pumped at 0.8 $\mathrm{mL} / \mathrm{min}^{-1}$. The eluted compounds were monitored at $254 \mathrm{~nm}$. The run time was 75 min.

HPLC (PDA Detector with empower software, Waters Corporation, Milford, USA) was used for the analysis of finished product samples and forced degradation and stability testing studies for Clobetasol propionate. The chromatographic column used was X Bridge C $18,4.6 \times 250 \mathrm{~mm} 5 \mu \mathrm{m}$. The separation was achieved on a gradient method. $0.05 \mathrm{M}$ of sodium phosphate buffer adjusted to 
$\mathrm{pH} 5.5$ was used as a buffer and ratio of methanol: acetonitrile $(10: 90 \mathrm{v} / \mathrm{v})$ was used as a mobile phase B. The HPLC gradient program was set as Time (min)/\% solution B: $0.0 / 40,12 / 40,35 / 65,40 / 65,45 / 40,55 / 40$. The column temperature was maintained at $40^{\circ} \mathrm{C}$ and the injection volume was $20 \mu \mathrm{L}$. Methanol and a mixture of Milli-Q water in the proportion of 70:30 $(\mathrm{v} / \mathrm{v})$; respectively used as Diluent. The mobile phase pumped at $1.00 \mathrm{~mL} / \mathrm{min}^{-1}$. The eluted compounds were monitored at $240 \mathrm{~nm}$. The run time was $55 \mathrm{~min}$.

HPLC (PDA Detector with empower software, Waters Corporation, Milford, USA) was used for the analysis of finished product samples and forced degradation and stability testing studies for Desonide. The chromatographic column used was Inertsil ODS-3V, $4.6 \times 250 \mathrm{~mm} 5.0 \mu \mathrm{m}$ particle size, Manufacturer: GL Sciences. The separation was achieved on a gradient method. $0.05 \mathrm{M}$ of potassium phosphate monobasic buffer adjusted to $\mathrm{pH} 4.5$ was used as a buffer and acetonitrile was used as a mobile phase B. The HPLC gradient program was set as Time $(\mathrm{min}) / \%$ solution B: $0.00 / 5,5.00 / 25,30.00 / 40,35.00 / 40,45.00 / 80$, $50.00 / 80,52.00 / 5,65.00 / 5.00$. The column temperature was maintained at $40^{\circ} \mathrm{C}$ and the injection volume was $20 \mu \mathrm{L}$. Acetonitrile used as Diluent. The mobile phase pumped at $1.00 \mathrm{~mL} / \mathrm{min}^{-1}$. The eluted compounds were monitored at 245 $\mathrm{nm}$. The run time was $65 \mathrm{~min}$.

\section{UPLC-MS/MS Method Development and Optimization}

In order to run the samples in UPLC-MS/MS method, it was decided to develop a method compatible for mass spectrometry. Sodium phosphate buffer used in the HPLC method is not compatible with UPLC-MS/MS. So that UPLC method was developed using volatile buffer ammonium formate and chromatographic conditions were optimized for the separation. Electrospray Ionization of positive ion mode was selected for the mass spectrometric analysis. Identical Pattern was reproduced using these conditions. To confirm the unknown peak of interest, elution pattern and \% area of the unknown peak in HPLC were compared against UPLC-MS/MS method and the respective retention times of unknown peaks were identified and confirmed.

\section{Liquid Chromatography and Mass Spectrometric Conditions}

LC-MS/MS system (Acquity UPLC coupled with TQD mass spectrometer with empower software, Waters Corporation, Milford, USA) was used for the identification of unknown compounds formed during forced degradation and stability testing studies for Hydrocortisone. The chromatographic column used was an Acquity UPLC BEH C18 $1.7 \mu \mathrm{m}, 3 \times 100 \mathrm{~mm}$. The separation was achieved on a gradient method. Ammonium formate buffer $(0.01 \mathrm{M})$ adjusted to $\mathrm{pH} 4.5$ was used as a buffer and acetonitrile was used as mobile phase B. The HPLC gradient program was set as Time (min)/\% solution B: 0.0/26, 6.83/26, 12.43/45, 18.83/70, $25 / 70,28 / 26,35 / 26$. The column temperature was maintained at $30^{\circ} \mathrm{C}$ and the injection volume was $5 \mu \mathrm{L}$. Acetonitrile and a mixture of milli-Q water in the 
proportion of $60: 40(\mathrm{v} / \mathrm{v})$; respectively was used as diluent. The mobile phase pumped at $0.3 \mathrm{~mL} / \mathrm{min}^{-1}$. The eluted compounds were monitored at $254 \mathrm{~nm}$. The run time was $35 \mathrm{~min}$. Mass spectrometric conditions optimized as cone gas $30 \mathrm{~V}$, cone value $30 \mathrm{~V}$, collision flow $50 \mathrm{~L} / \mathrm{Hr}$., ion energy 2 entrance and exit Potentials $1 \mathrm{~V}$, source temperature $130^{\circ} \mathrm{C}$, desolovation gas $300 \mathrm{~L} / \mathrm{hr}$., desolvation temperature $300^{\circ} \mathrm{C}$.

LC-MS/MS system (Acquity UPLC coupled with TQD mass spectrometer with empower software, Waters Corporation, Milford, USA) was used for the identification of unknown compounds formed during forced degradation and stability testing studies of clobetasol propionate. The chromatographic column used was an Acquity UPLC BEH C18 $1.7 \mu \mathrm{m}, 3 \times 100 \mathrm{~mm}$. The separation was achieved on a gradient method. Ammonium formate buffer $(0.01 \mathrm{M})$ adjusted to $\mathrm{pH} 5.25$ with $10 \%$ formic acid was used as a buffer and ratio of methanol:acetonitrile (10:90 (v/v) was used as a mobile phase B. The UPLC gradient program was set as Time (min)/\% solution B: 0.0/40, 2.00/40, 4.00/45, 14.00/65, $18.00 / 65,20.00 / 40,25.00 / 40$. The column temperature was maintained at $40^{\circ} \mathrm{C}$ and the injection volume was $5 \mu \mathrm{L}$. Acetonitrile and a mixture of Milli-Q water in the proportion of $60: 40(\mathrm{v} / \mathrm{v})$; respectively used as diluent. The mobile phase pumped at $0.4 \mathrm{~mL} / \mathrm{min}^{-1}$. The eluted compounds were monitored at $240 \mathrm{~nm}$. The run time was $25 \mathrm{~min}$. Mass spectrometric conditions optimized as cone gas $30 \mathrm{~V}$, cone value $30 \mathrm{~V}$, collision flow $50 \mathrm{~L} / \mathrm{Hr}$., ion energy 2 entrance and exit Potentials $1 \mathrm{~V}$, source temperature $130^{\circ} \mathrm{C}$, desolovation gas $300 \mathrm{~L} / \mathrm{hr}$., desolvation temperature $300^{\circ} \mathrm{C}$.

LC-MS/MS system (Acquity UPLC coupled with TQD mass spectrometer with empower software, Waters Corporation, Milford, USA) was used for the identification of unknown compounds formed during forced degradation and stability testing studies of Desonide. The chromatographic column used was an Acquity UPLC BEH C18 $1.7 \mu \mathrm{m}, 3 \times 100 \mathrm{~mm}$. The separation was achieved on a gradient method. Ammonium formate buffer $(0.01 \mathrm{M})$ adjusted to $\mathrm{pH} 4.48$ with $10 \%$ formic acid was used as a buffer and ratio of methanol:acetonitrile (20:80 $(\mathrm{v} / \mathrm{v})$ ) was used as a mobile phase B. The UPLC gradient program was set as Time (min)/\% solution B: $0.0 / 5.00,2.00 / 25,12.00 / 35,15.00 / 35,20.00 / 80$, $25.00 / 80,27.00 / 5,33.00 / 5.00$. The column temperature was maintained at $40^{\circ} \mathrm{C}$ and the injection volume was $5 \mu \mathrm{L}$. Acetonitrile used as diluent. The mobile phase was pumped at $0.4 \mathrm{~mL} / \mathrm{min}^{-1}$. The eluted compounds were monitored at $240 \mathrm{~nm}$. The run time was $33 \mathrm{~min}$. Mass spectrometric conditions optimized as cone gas $30 \mathrm{~V}$, cone value $30 \mathrm{~V}$, collision flow $50 \mathrm{~L} / \mathrm{Hr}$., ion energy 2 entrance and exit Potentials $1 \mathrm{~V}$, source temperature $130^{\circ} \mathrm{C}$, desolovation gas $300 \mathrm{~L} / \mathrm{hr}$., desolvation temperature $300^{\circ} \mathrm{C}$.

\section{Degradation of Corticosteroids}

There were several degradation mechanisms reported for corticosteroids especially with the D ring and 1,3-dihydroxyacetone side chains [3] [27] [28] [29] 
[30] [31]. Betamethasone and Dexamethasone form corresponding enol aldehydes and carboxylic acid impurities during the stability in the transdermal dosage and in solutions. The introduction of the phosphoric group at the 21-hydroxyl of the steroid core structures might impart additional degradation pathways to the resulting phosphonosteroids.

\subsection{Enol-Aldehyde Degradation-Mattox Rearrangement}

Enol aldehydes are one type of key degradants and metabolic intermediates formed from a group of corticosteroids containing the 1,3-dihydroxyacetone side chain on their D-rings, such as Betamethasone, Dexamethasone, Beclomethasone, and related compounds [27] [28] [29] [30]. The formation of enol aldehydes from these corticosteroids is via acid-catalyzed $\beta$-elimination of water from the side chain, a process known as Mattox rearrangement (Figure 5). Bin Chen et al. reported that enol aldehydes could also be formed directly from the corresponding 17,21-diesters of these corticosteroids but only under alkaline condition, which was proposed to follow a variation pathway of the original Mattox rearrangement. Bin Chen et al. proposed the mattox rearrangement in both acidic conditions as well as in basic conditions. The characteristic UV Spectra (Figure 6) is the informal identification for the formation of these impurities due to mattox rearrangement. This impurity was also observed in the degradation of Clobetasol propionate and Desonide in the transdermal dosage forms.

\subsection{Hydrocortisone Degradation}

Jen Hansen et al. reported the degradation pattern of Hydrocortisone and its major degradation products in aqueous solution was investigated utilizing an HPLC method [19]. The product distribution was characterized qualitatively and quantitatively as a function of $\mathrm{pH}$ in the range $0-11$, nature of buffers and trace metal impurities. Two major decomposition pathways were reported, an oxidative degradation leading to the formation of 21-dehydrohydrocortisone which subsequently degraded to a 17-carboxylic acid and a 17,20-dihydroxy-21-carboxylic acid derivative, and a non-oxidative reaction giving a 17-oxo, 17-deoxy21-aldehyde and 17-deoxy-20-hydroxy-21-carboxylic acid derivative. HPLC and UPLC-MS/MS methods were developed and performed the forced degradation study and stability sample analysis of Hydrocortisone in otic solution [10] [24]

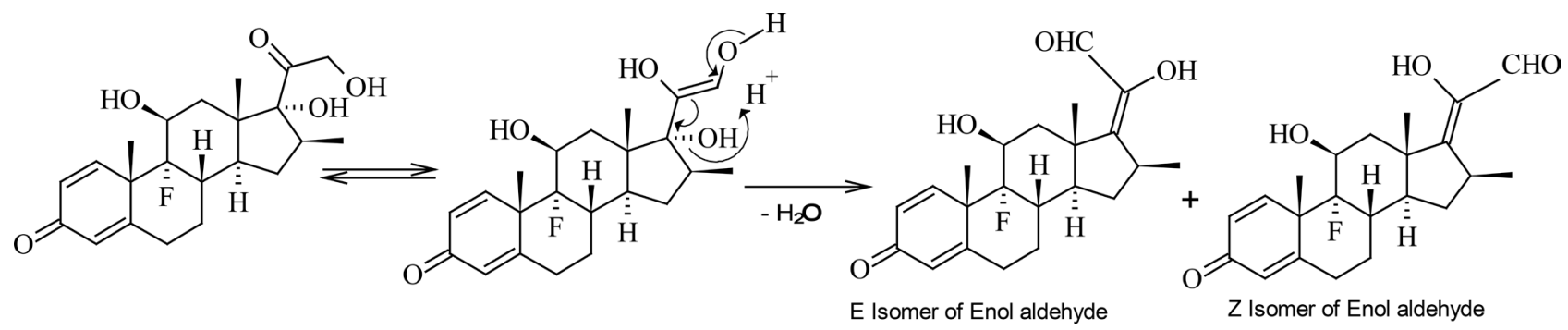

Figure 5. Enol-Aldehyde: Mattox Rearrangement. 


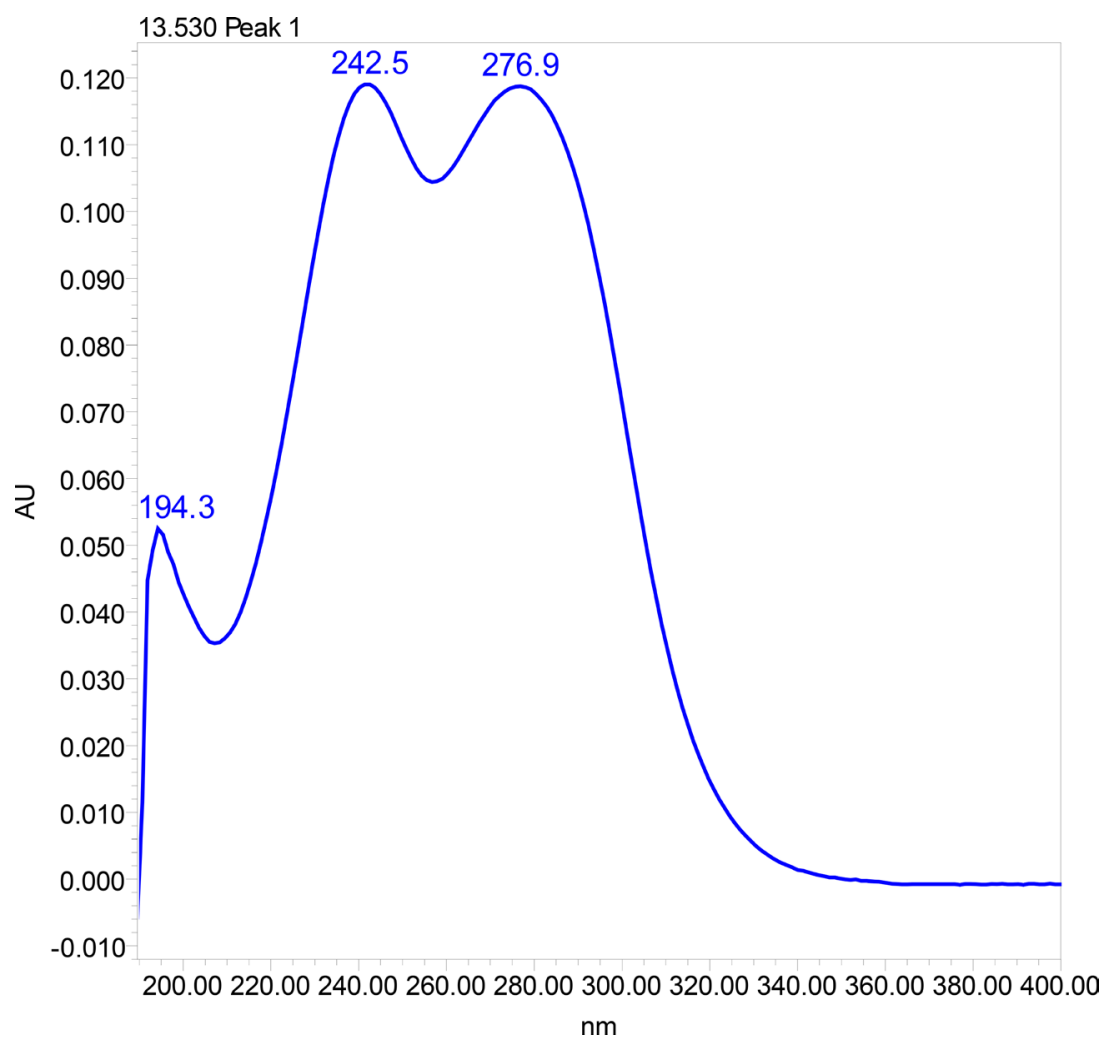

Figure 6. Characteristic UV spectra of Enol-Aldehyde Impurity.

[25]. During the stability studies testing of the otic solution, two unknown impurities was observed, one unknown impurity was identified as a keto-hydrocortisone impurity whereas the other impurity was identified as Hydrocortisone acid impurity. These two impurities were identified by UPLC-MS/MS fragmentation pattern and by NMR evaluation.

\subsection{Clobetasol Propionate Degradation}

Clobetasol propionate degradation behavior was studied in the lotion, ointment and topical solution. Ayesha et al. reported forced degradation of Clobetasol propionate in various solvents but there was no detailed identification of the degradation reported [32]. Forced degradation study and stability analysis of Clobetasol propionate in different dosage forms were performed using HPLC and UPLC-MS/MS and possible major degradants were identified. Possible mechanisms for the degradation behavior were drafted and one unknown impurity in the topical solution identified as Clobetasol acetic acid impurity was characterized by LCMSMS and NMR studies [11] [12] [13] [33]. Extensive studies were conducted evaluating different residual solvents and excipients' interaction with the drug in order to identify the root cause of the generation of these impurities.

\subsection{Desonide Degradation}

HPLC and UPLC analysis was performed for Desonide finished product samples (lotion, ointment and cream). Based on the excipients and the sample prepara- 
tion involved, three different HPLC methods were developed for three different formulations. Forced degradation study and stability analysis of Desonide in different dosage forms performed using HPLC and UPLC-MS/MS and possible major degradants identified. Possible mechanisms for the degradation identified. One unknown impurity identified in the lotion as methoxy impurity of the Desonide. All the other impurities were separated using the developed HPLC method.

\section{Results and Discussion}

\subsection{Hydrocortisone}

Literature studies indicated that 21-dehydrohydrocortisone was the principal degradation product of hydrocortisone formed at $50^{\circ} \mathrm{C}$ and room temperature [31] [32] [33]. Significant amounts of the 17-ketosteroid (11) and small amounts of the acid (VI) were detected in samples stored at $50^{\circ} \mathrm{C}$ in Hydrocortisone lotion. Forced degradation study and drug stability studies in the accelerated conditions of Hydrocortisone otic solution formed major impurities as hydrocortisone acetate, cortisone 17 keto steroid impurity and one unknown impurity (Figure 7). 17-Keto steroid impurity was identified by LC-MS/MS spectral pattern (Figure 8). The mass of unknown impurity was identified as 377 in the positive mode (Figure 9). The retention behavior and spectral pattern indicate that it could be a polar impurity when compared to Hydrocortisone. Mass spectrum of the unknown was compared against Hydrocortisone (Figure 10). Molecular ion fragments of 267, 285, 295 and 313 confirm the presence of the side chain. $\mathrm{H}$ NMR spectrum confirms the presence of aldehyde and carboxylic acid proton at singlet 8.9 and broad hump at 9.10 respectively (Figure 11 ). The formation of the impurity is due to the oxidation of the Hydrocortisone which involves the Baeyer-Villiger oxidation which forms the hydroxyl group into aldehyde group (Figure 12).

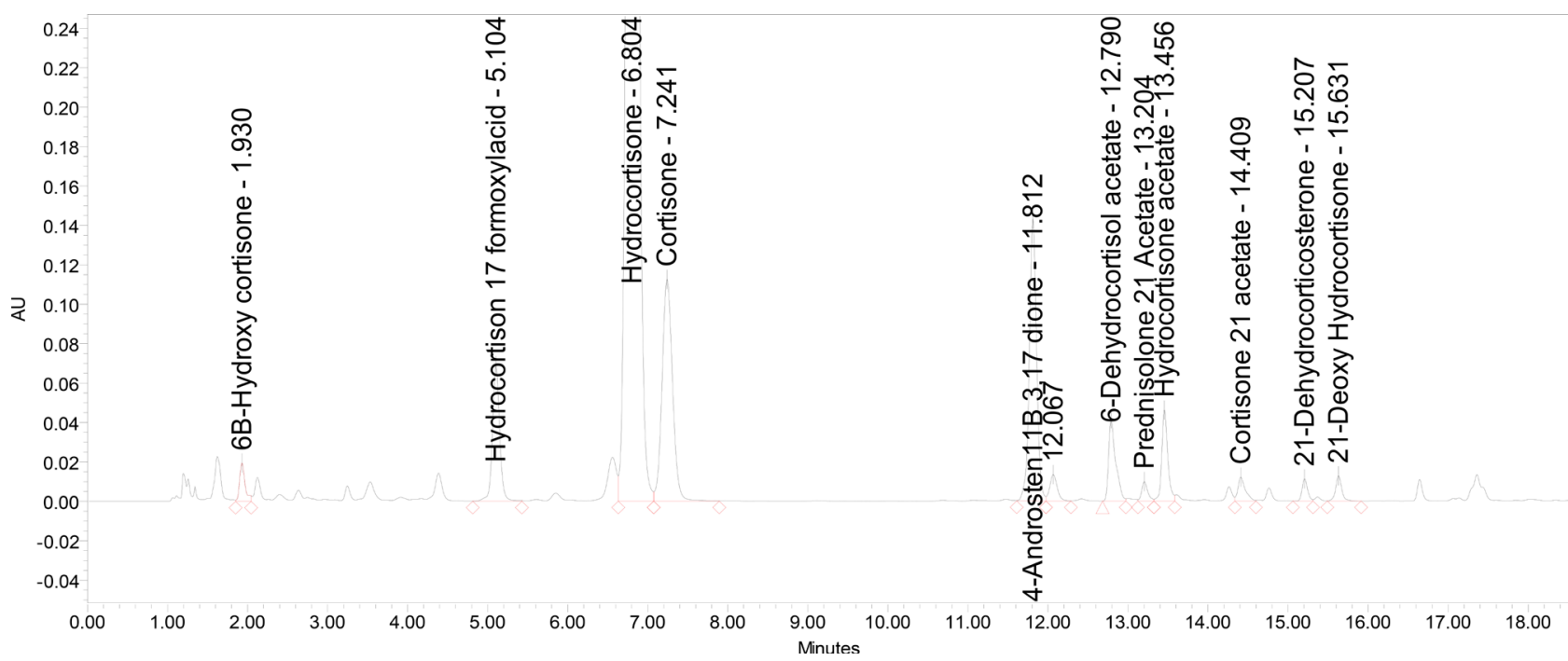

Figure 7. UPLC-MS/MS (PDA) Chromatogram of the Hydrocortisone stability sample. 


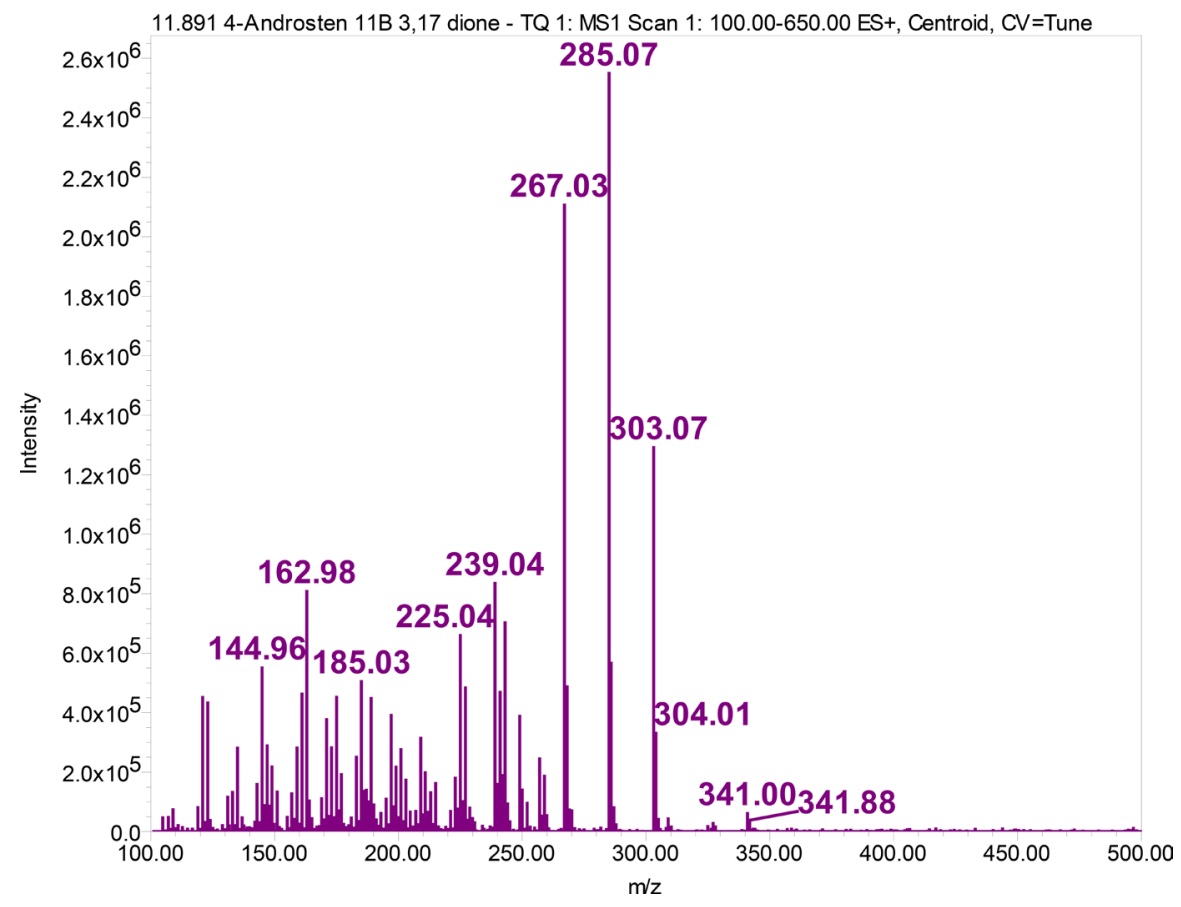

Figure 8. MS/MS Chromatogram of the keto impurity of the Hydrocortisone.

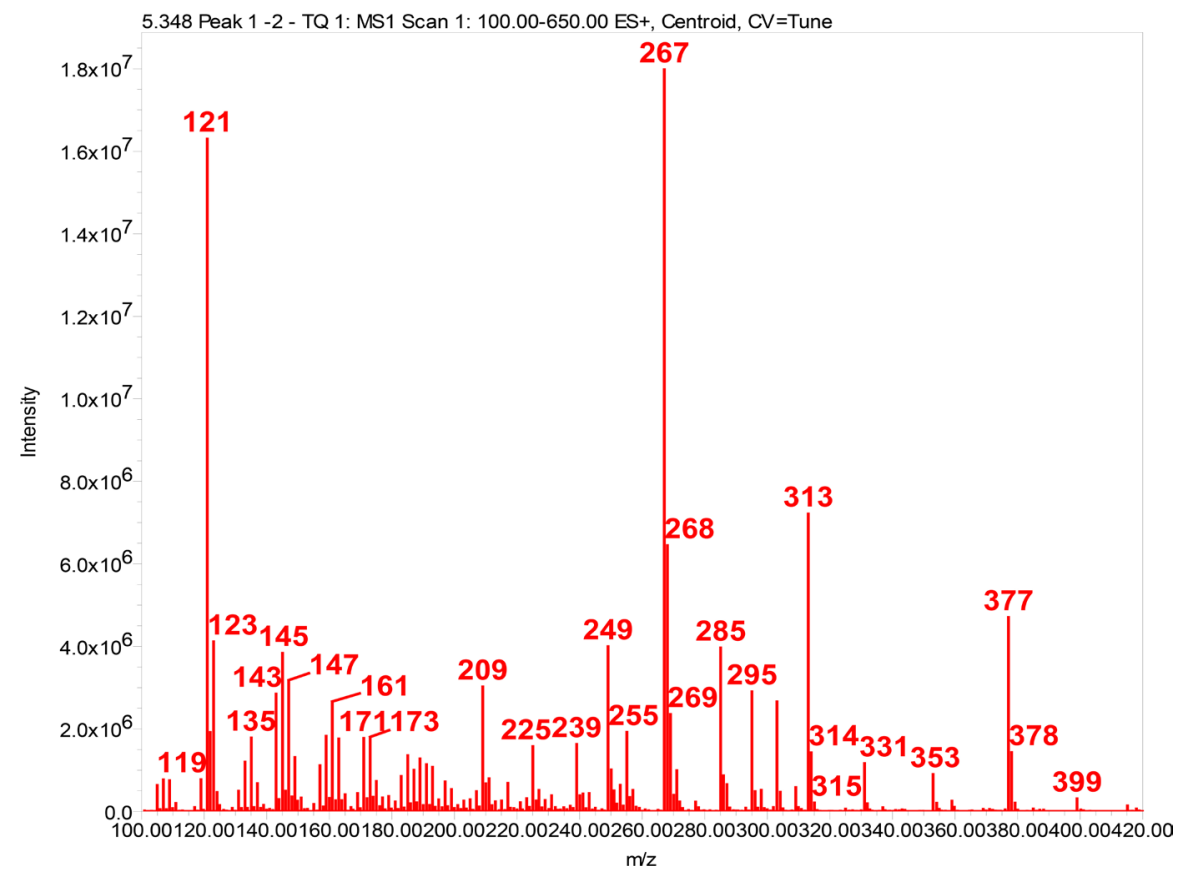

Figure 9. UPLC-MS/MS Chromatogram of the formoxyl acid impurity.

\subsection{Clobetasol Propionate}

Clobetasol propionate formed several impurities during the forced degradation and in the finished product stability studies. Impurity profiling of the ointment, lotion and topical solution were studied in detail (Figure 13). During the stability analysis of these dosage forms, Clobetasol tend to form USP Related Compound A due to the keto enol tautomeric rearrangement followed by the dehydration 


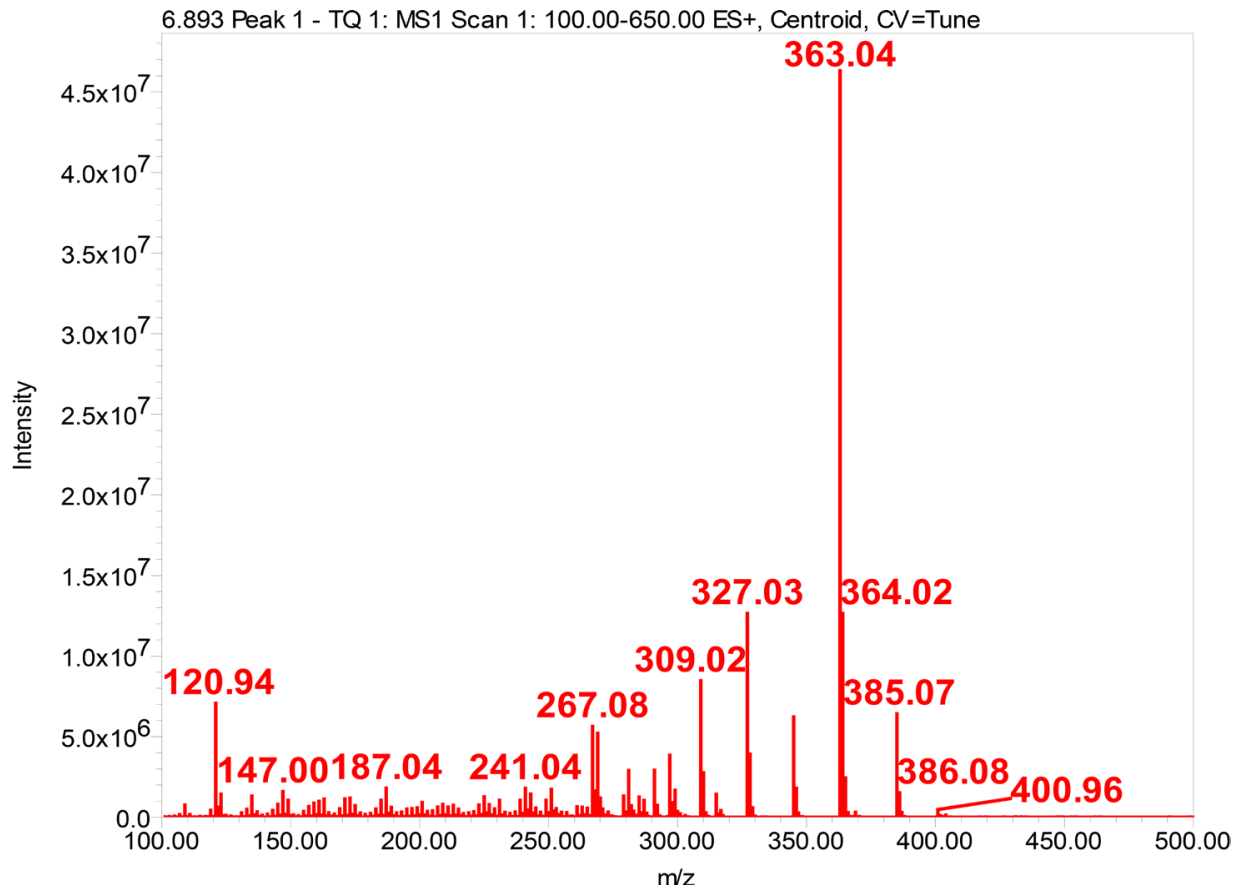

Figure 10. MS/MS Chromatogram of the Hydrocortisone.

2083-096A5 1H NMR in DMSO-d6

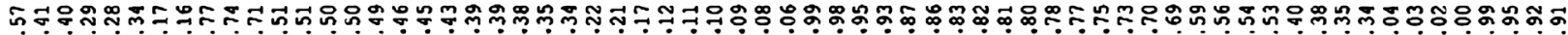

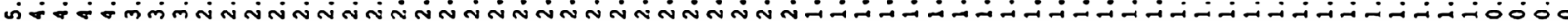

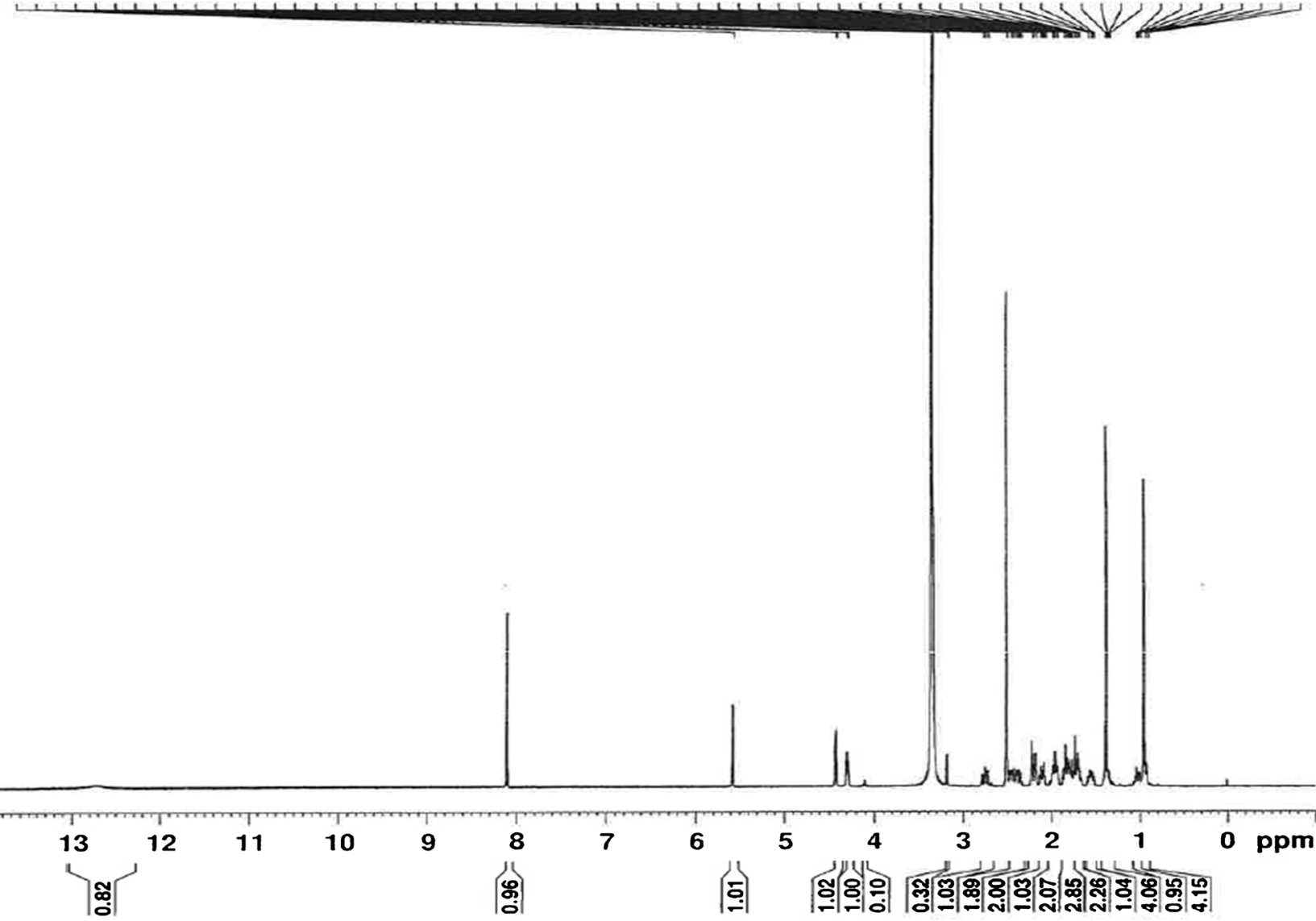

Figure 11. H NMR spectrum of the formoxyl acid impurity. 


\section{Degradation Mechanism of Hydrocortisone}
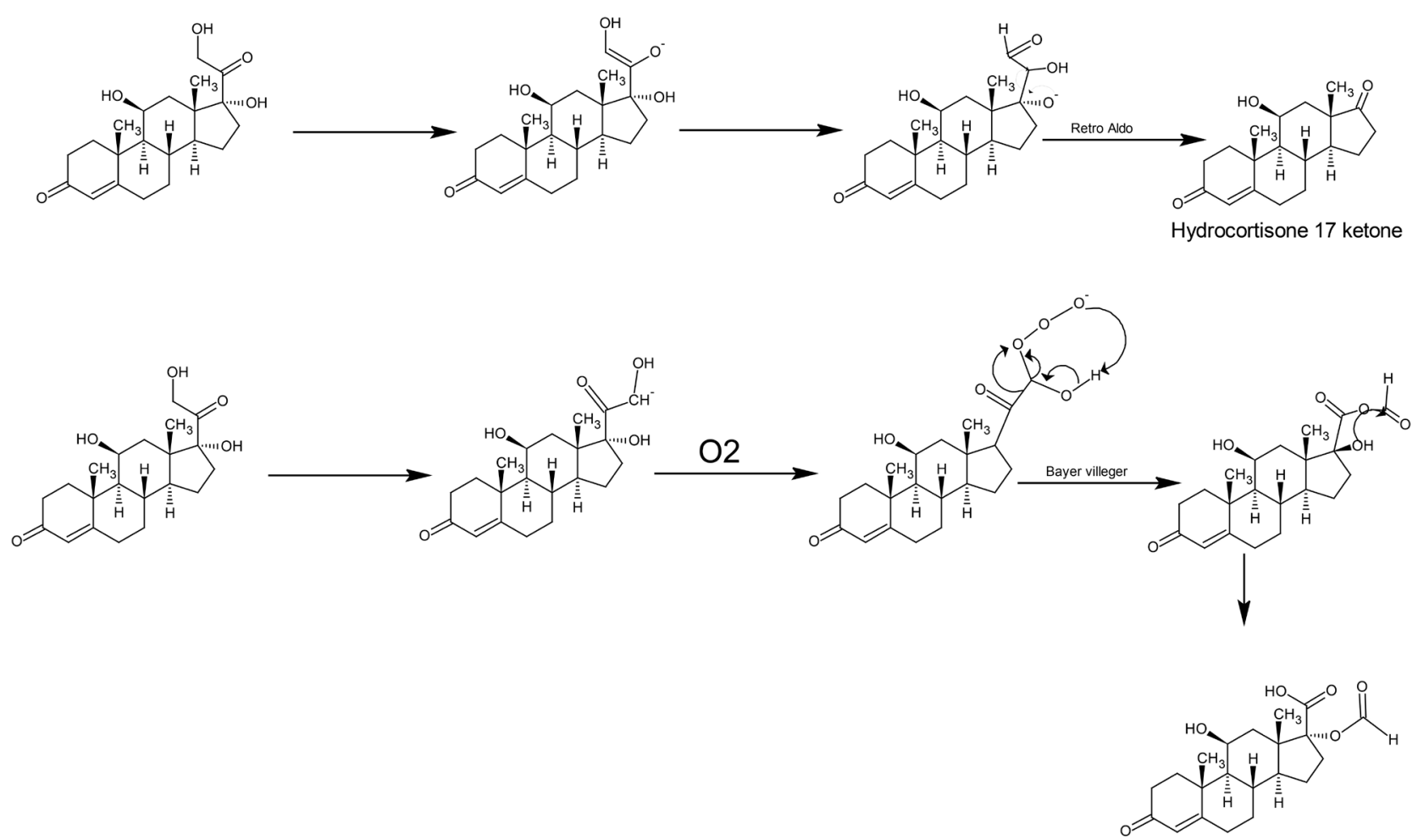

Hydrocortisone 17-formyloxy-17 acid

Figure 12. Mechanism of Hydrocortisone via Baeyer-Villiger oxidation.

reaction to form a cyclic compound (Figure 14 \& Figure 15). Clobetasol propionate topical solution generates the same impurity at a very minimal level. The nominal degradants of the topical solution are delta chloro impurity and Clobetasol beta chloro diene impurity which will form due to the loss of hydroxy group at 17 position. Another major unknown degradant observed during the stability sample analysis of the topical solution was later identified as an acetic acid impurity. LC-MS/MS analysis was performed and the molecular ion of the peak was found as 374 (Figure 16). Several possibilities of degradation pattern were drawn with the identified mass number and through which all the possible impurities were injected to identify the unknown impurity (Figure 17). Unknown impurity characterization was performed by the UPLC-MS/MS and $\mathrm{H}$ NMR analysis (Figure 18 \& Figure 19).

Structural confirmation and chemical shift assignments of the acetic acid impurity was achieved from the analyses of $\mathrm{H}$ NMR, in conjunction with mass spectral information. Analysis of NMR data clearly showed the absence the resonances due to the chloromethyl ketone and propionate ester moieties in the degradant as compared to the API. An olefin proton resonance was observed at $5.42 \mathrm{ppm}(\mathrm{H}-21)$. In addition, the singlet at $5.42 \mathrm{ppm}$ also showed a C correlation to the carbonyl carbon at $170.9 \mathrm{ppm}$ (C-22), consistent with the carboxyl carbonyl carbon. The stereochemistry around C17 - C21 double bond could not 
K. K. Hotha et al.

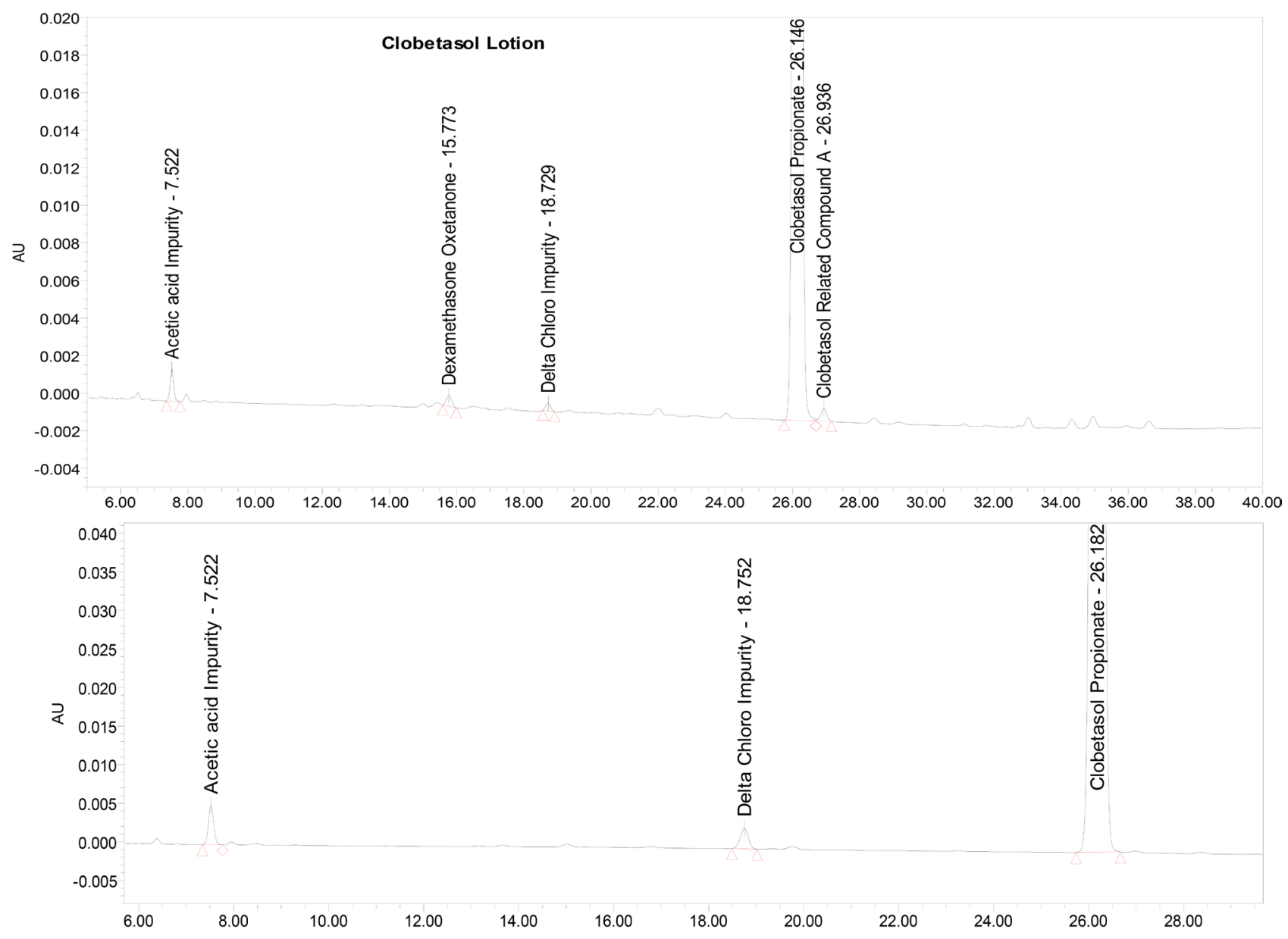

Figure 13. Stability sample results of Clobetasol Propionate formulations.

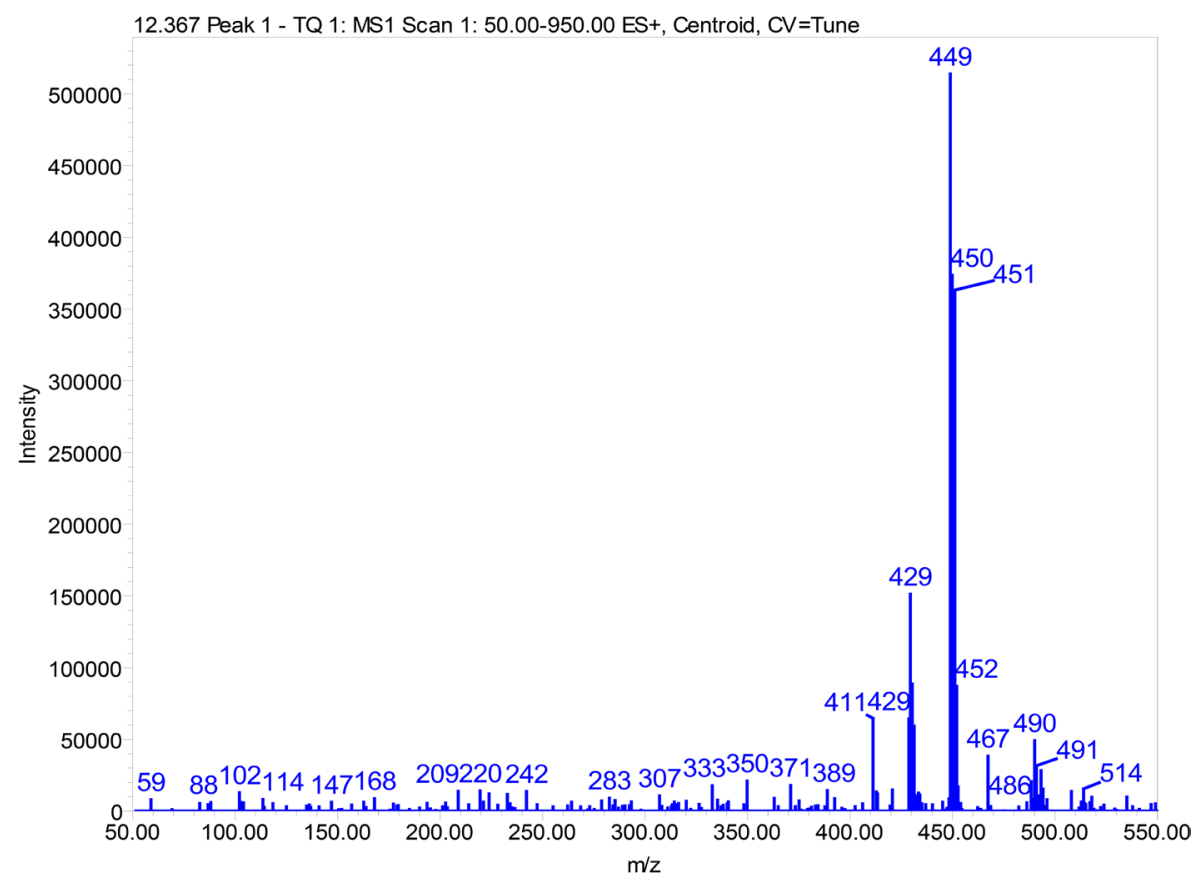

Figure 14. MS/MS spectral Pattern of Clobetasol related compound-A. 


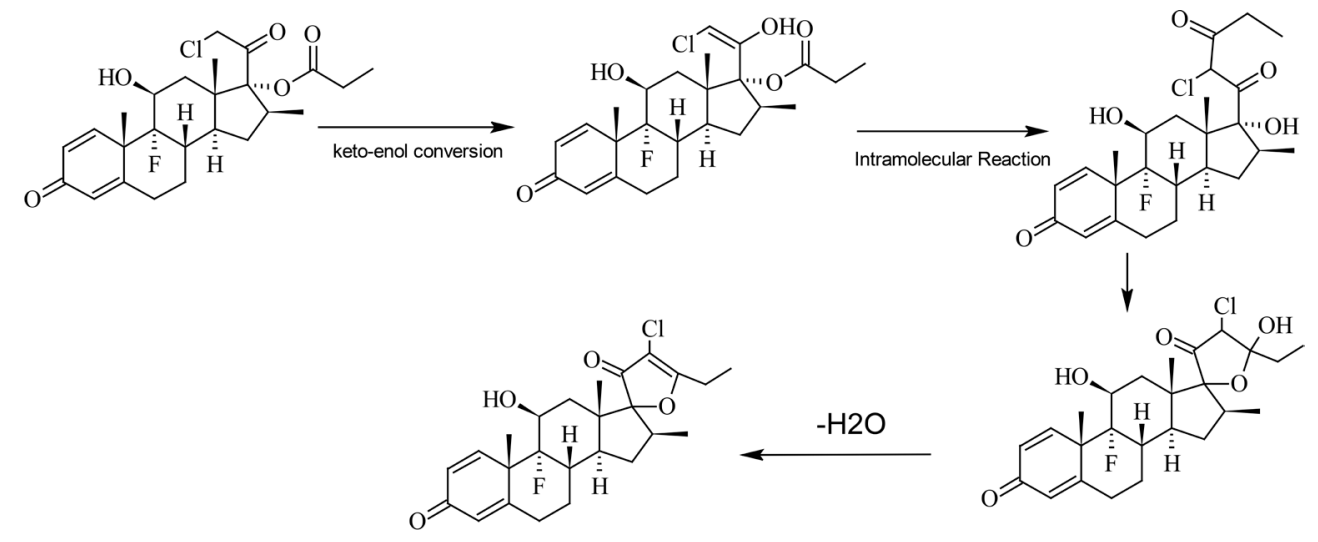

Figure 15. Mechanism of Impurity-A formation from clobetasol propionate.

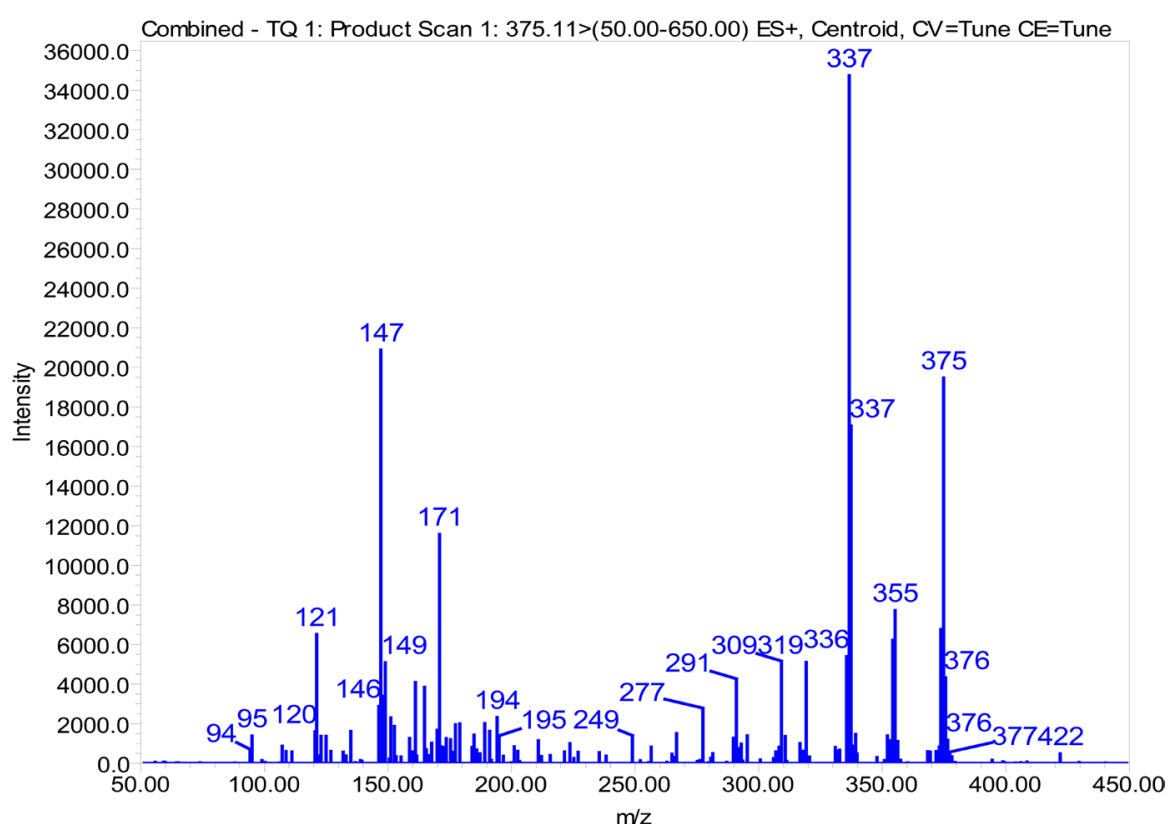

Figure 16. MS/MS spectral pattern of the unknown impurity.

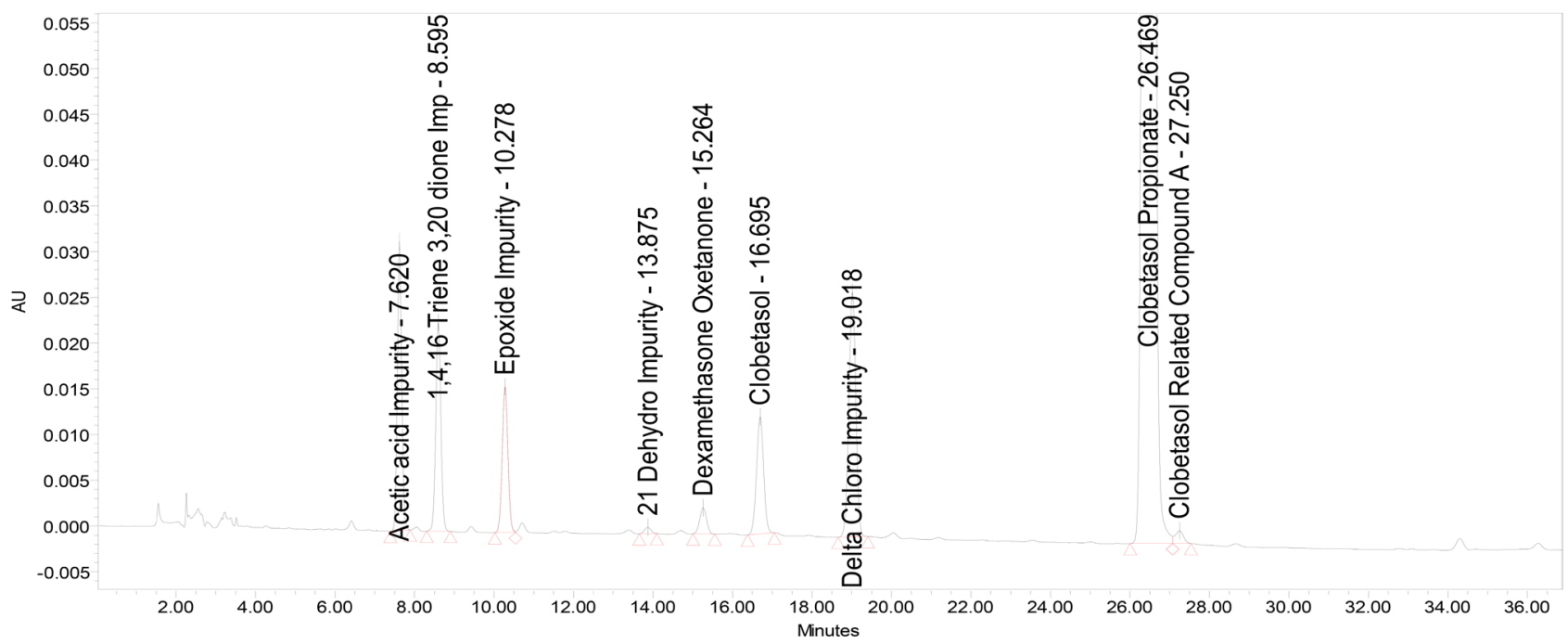

Figure 17. Spiking of the possible MW 374 degradants and related impurities in the Clobetasol spiking solution. 


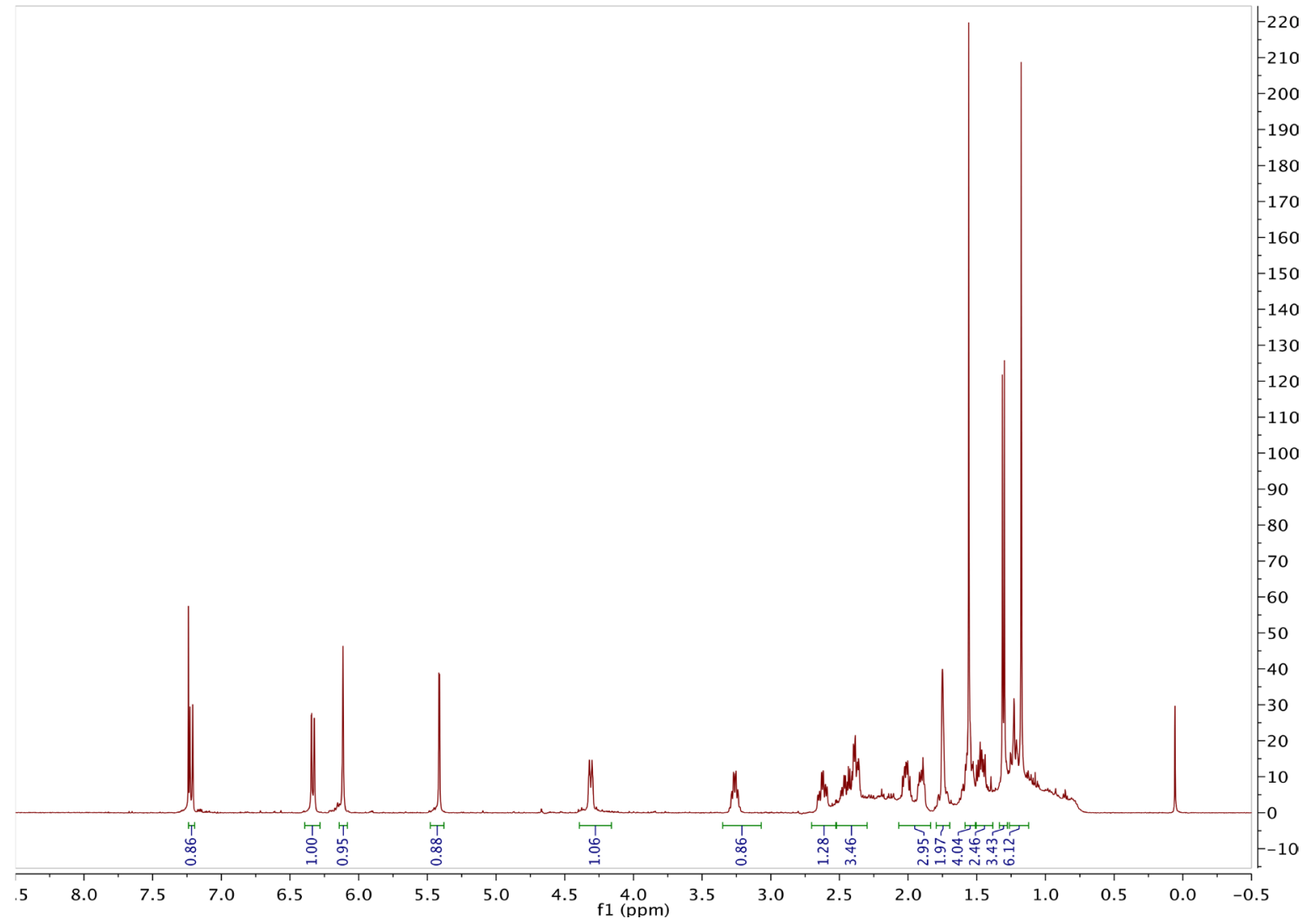

Figure 18. H NMR spectrum of acetic acid impurity.

\begin{tabular}{|c|c|c|c|c|c|c|c|}
\hline 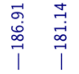 & $\begin{array}{ll}\infty & 0 \\
0 & 0 \\
0 & 0 \\
0 & 0 \\
1 & 1\end{array}$ & $\stackrel{\substack{\sim\\
}}{\stackrel{\Gamma}{\Gamma}}$ & 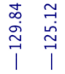 & $\begin{array}{l}\stackrel{\circ}{\circ} \\
\stackrel{0}{0} \\
1\end{array}$ & 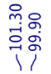 & 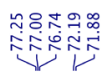 & 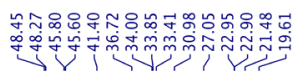 \\
\hline
\end{tabular}

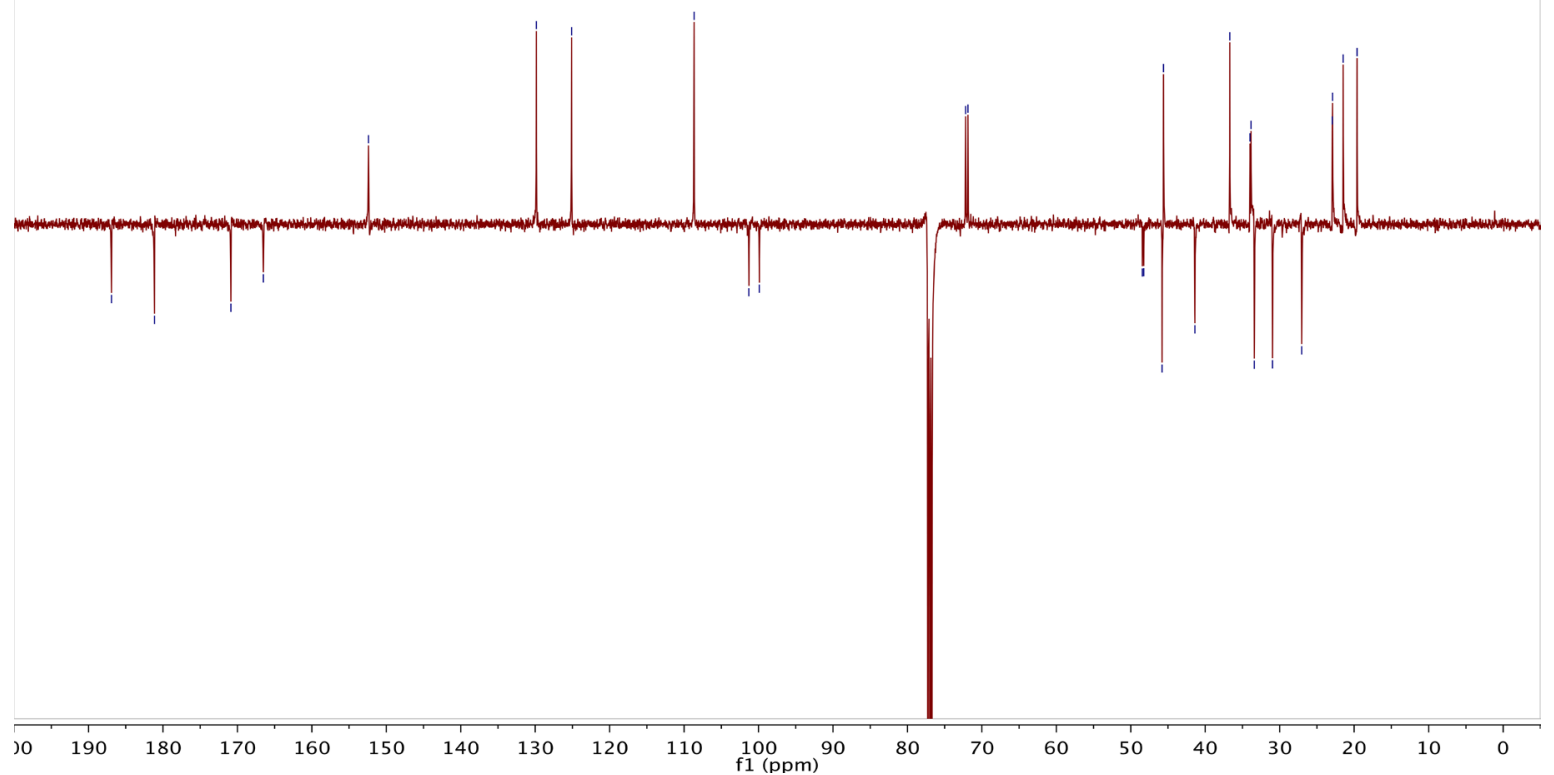

Figure 19. C13 NMR Spectrum of the acetic acid impurity. 
be confirmed by NMR experiments Which indicates because of the steric hindrance, the bulky $-\mathrm{COOH}$ group is expected to be away from the C-18 methyl group and shown as drawn. Analysis of the NMR data also revealed that there are no structural modifications in $\mathrm{A}, \mathrm{B}$, and $\mathrm{C}$ ring moieties of the degradant. The only structural changes observed are with respect to the substituents attached to $\mathrm{C} 17$ position of the molecule. Mass spectral characterization was performed for this impurity and observed that the molecular ions of 355 (M-HF), 337 (M-HF+H2O), 319 (M-HF-2H2O), 171 (Cleavage in the B ring) and 121 (Cleavage at the $\mathrm{C}$ ring) confirm the structure of acetic acid impurity. Mechanism involves formation of enol aldehyde through intra molecular cannizaro reaction (Figure 20).

Mechanistic pathways of acetic acid impurity and USP related compound A is explained in (Figure 15 \& Figure 20). Excipients composition, $\mathrm{pH}$ are the two important considerations in identifying the probable degradants in the Clobetasol transdermal dosage forms. Trace level residual solvents like DMF, methanol, THF which were during the synthetic manufacturing process could degrade Clobetasol when it is in the solution form. Clobetasol ointment predominantly forms related compound A whereas topical solution forms Clobetasol acetic acid as a major impurity. Water absorption, basic nature of the excipients and solution $\mathrm{pH}$ range are the clear-cut root causes for the formation of the Clobetasol related degradants in finished product. Clobetasol related compound B (Delta Chloro Impurity), Clobetasol related compound A (3, 3 Dione impurity), delta hydroxy impurity, 21 dehydro 17 deoxy betamethasone, dexamethasone oxetanone, enol aldehyde isomer 17 deoxy dexamethasone, Clobetasol and delta
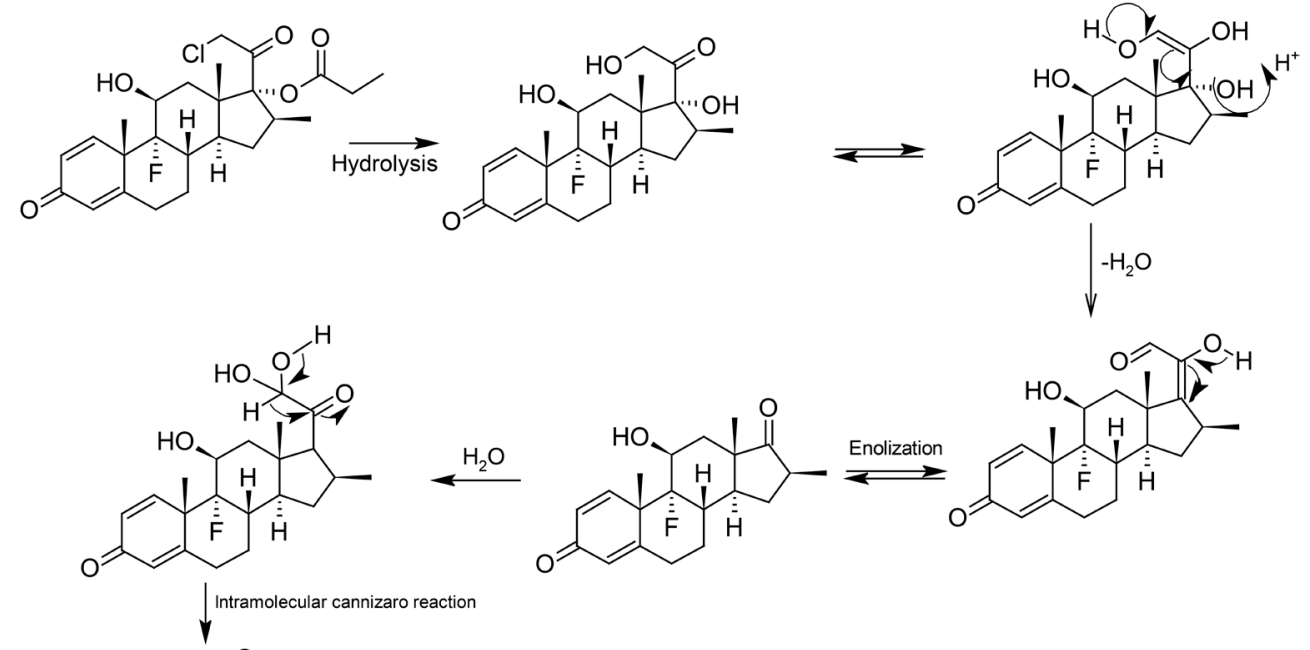<smiles>CC1C[C@H]2[C@@H]3CCC4=CC(=O)C=C[C@]4(C)[C@@]3(F)C(O)C[C@]2(C)[C@]1(C)C(=O)O</smiles><smiles>CC1C[C@H]2[C@H]3CCC4=CC(=O)C=C[C@]4(C)[C@]3(F)C(O)C[C@]2(C)/C1=C/C(=O)O</smiles>

Figure 20. Mechanism of acetic acid impurity formation in Clobetasol Propionate. 
chloro impurity were evaluated during the impurity profiling of the topical solution. All the impurities were separated using HPLC and characterized using LC-MS/MS and NMR.

\subsection{Desonide}

Desonide-21-dehydro is found to be the major known acid degradant and 16-Alpha-Hydroxy prednisolone is found to be major known base degradant generated during the forced degradation studies. Based on the degradation data, it was found Desonide to be sensitive to both acid and base degradation (Figures 21-23). Presence of methanol in the diluent or in the pharmaceutical dosage form degrades Desonide to methoxy degradant of Desonide (Figure 24). This impurity could be generated from the 21 dehydro compound which reacts with methanol group to form the methoxy impurity. Mass spectral fragmentation was performed and compared against Desonide Mass spectrum (Figure 25). Molecular ions of 432, 415 confirms the loss of methyl group and the presence of the methoxy group on the C-17 Sidechain (Figure 26).

The degradants generated during the forced degradation and stability indicating studies of three corticosteroids in different topical formulations were investigated. Generally, the excipients used in the RLD are presumed compatible with the drug substance. However, the formulator should be aware that different vendors or grades may contain different impurities, which in turn may trigger the drug degradation. Development of the Corticosteroid topical formulations require extensive knowledge in the area of excipients, rheological and process optimization. Excipient compatibility data, stability profile of a R\&D batch and characterization of the RLD in terms of drug product stability profile are needed to increase the chances of success in pharmaceutical development and to substantiate the stability data generated in the formal stability program.

In overview, during the development of the Clobetasol topical solution and ointment several critical factors were identified which caused the chemical degradation. Presence of trace level of organic residual solvents like DMF, THF caused the formation of acetic acid impurity which was above the identification threshold. Trace level of absorption of water in the non-aqueous formulation of Clobetasol Propionate resulted in the formation of the 3, 320 Dione impurity which is major degradation product in the base hydrolysis and water hydrolysis of force degradation studies. Desonide is stable in the semisolid dosage forms. The selection of the petrolatum is the major challenge for the ointments which are dispersed in the petrolatum bases. It should be noted that Desonide 21 dehydro impurity the major degradant observed in Desonide formulation is a common impurity in majority of the corticosteroids. Also, presence of methanol as a residual solvent or in diluent can form methoxy impurity in Desonide formulations. The Hydrocortisone was very unstable in water and water-washable ointment base. The addition of alcohol and glycerin to water had a stabilizing effect. When subject to drastic degradations conditions (very acidic or very basic 


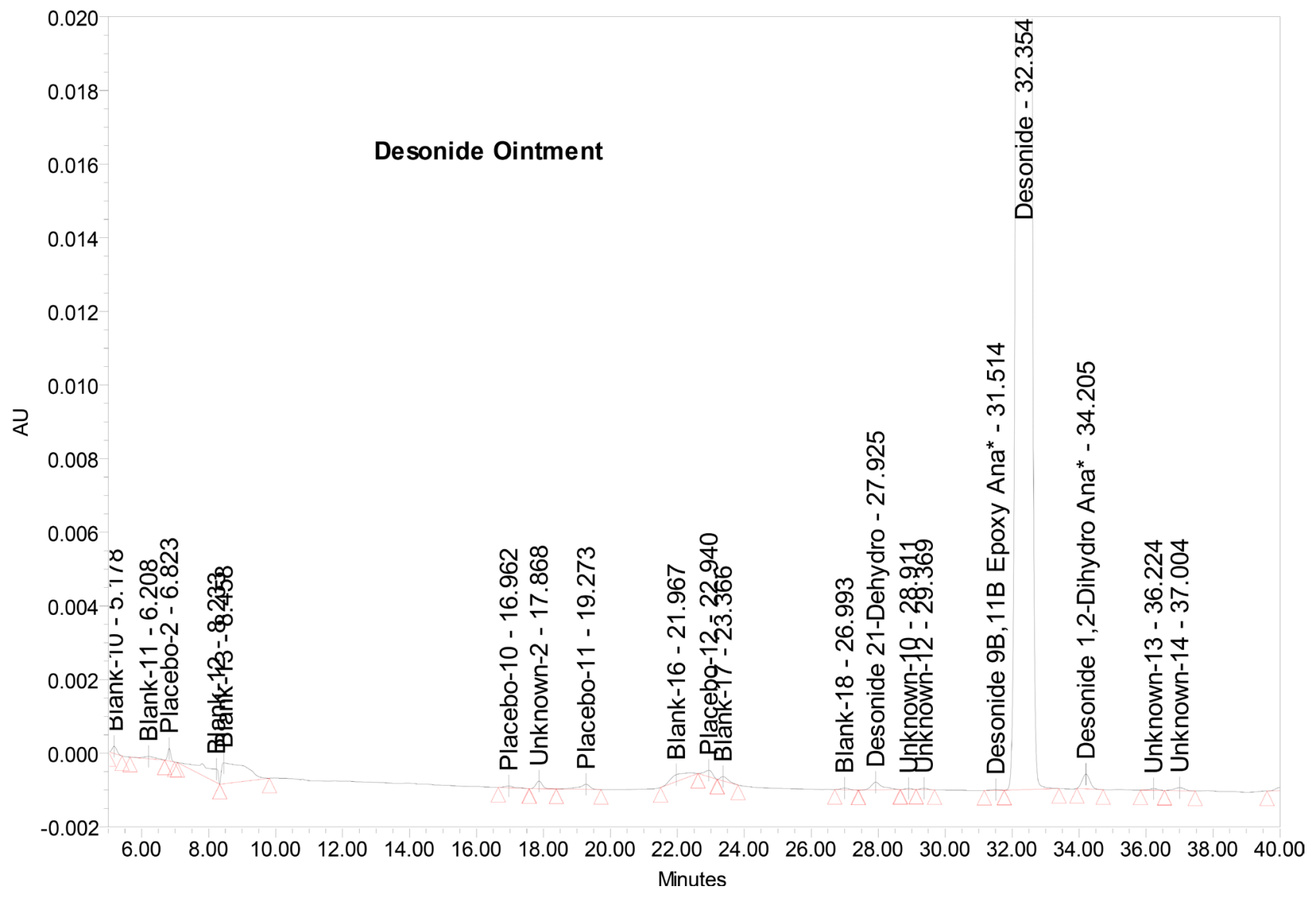

Figure 21. Desonide Ointment sample chromatogram.

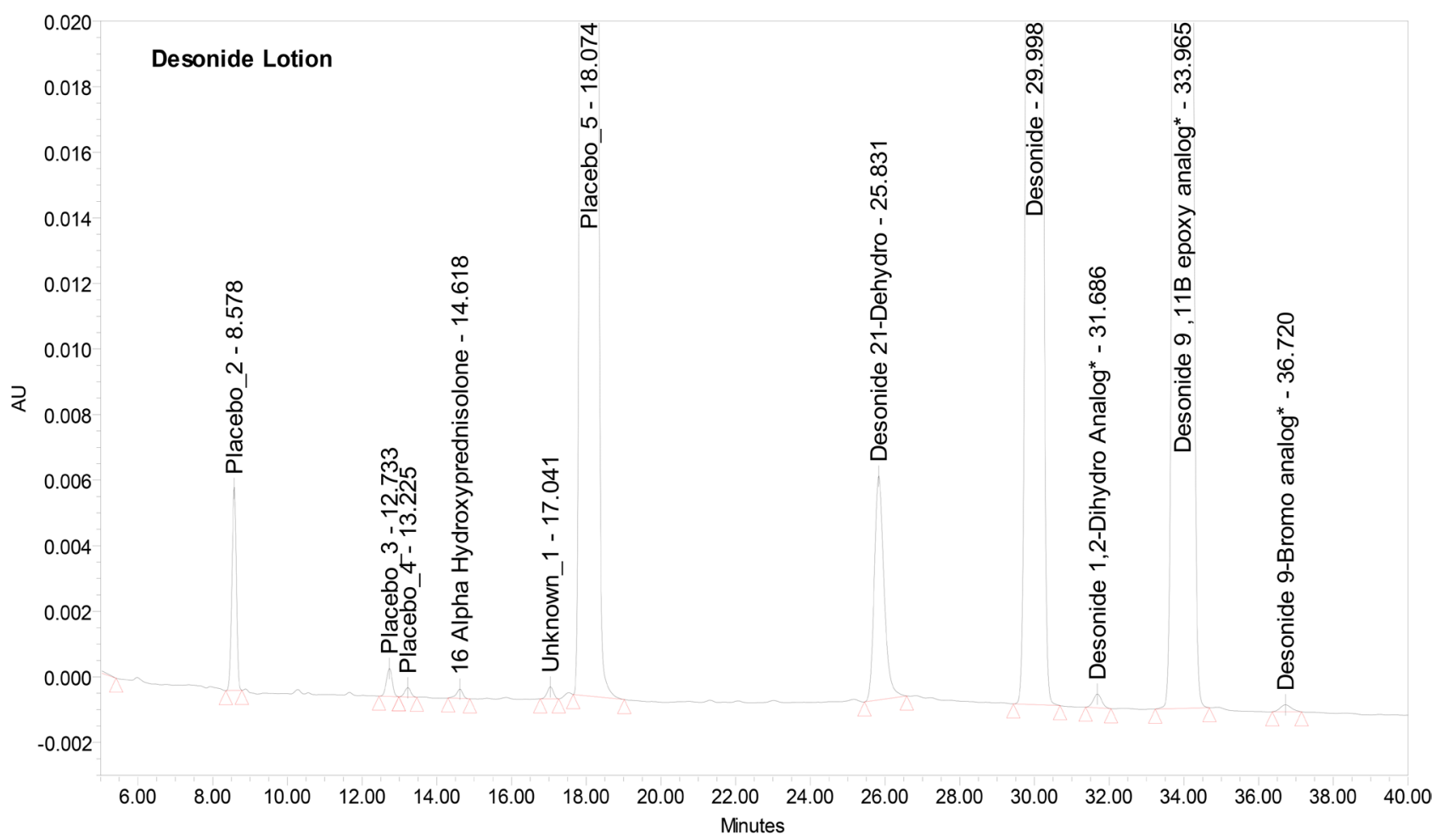

Figure 22. Desonide Lotion sample chromatogram. 


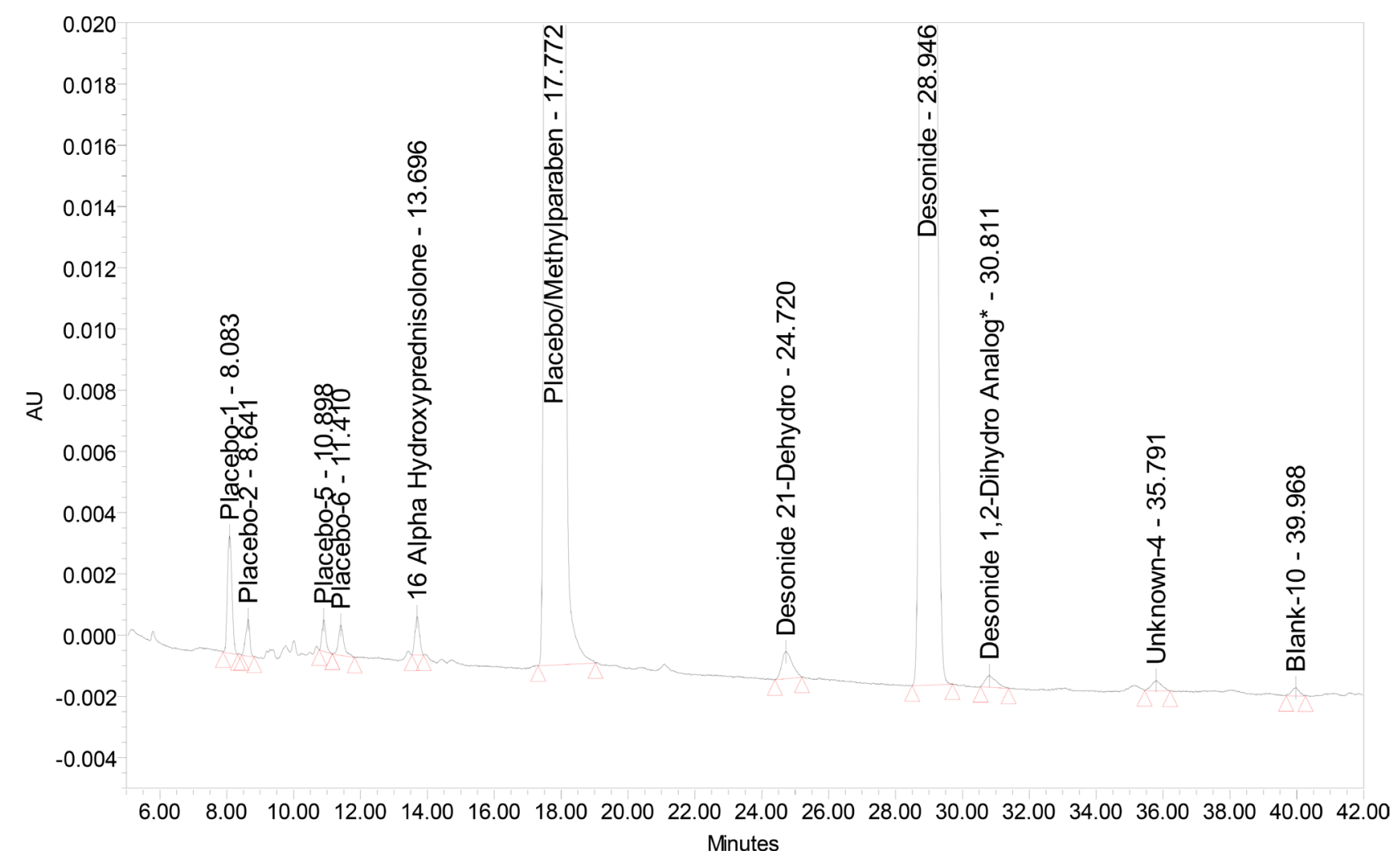

Figure 23. Desonide Cream sample chromatogram.

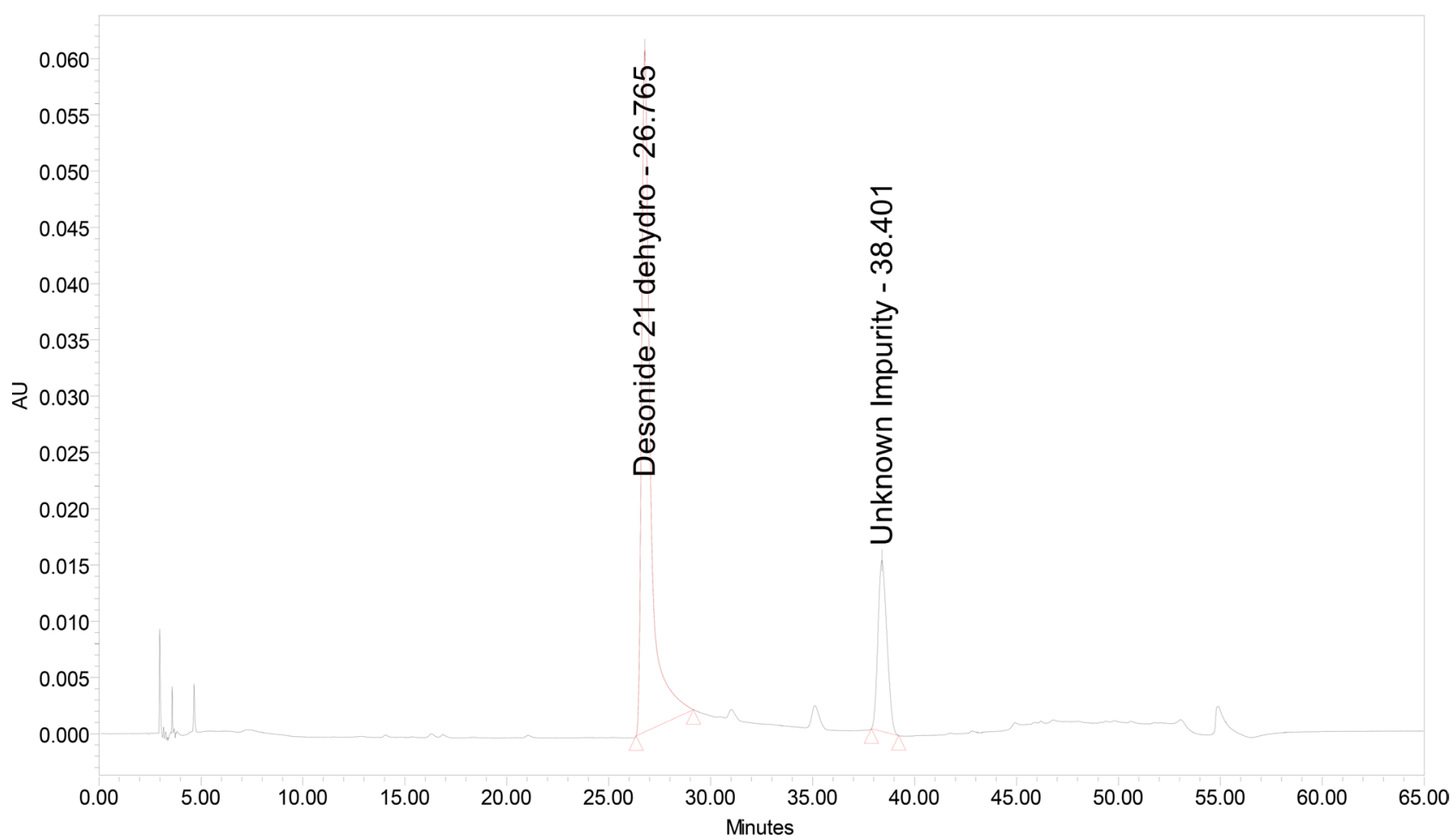

Figure 24. Degradation of Desonide 21 dehydro impurity chromatogram. 


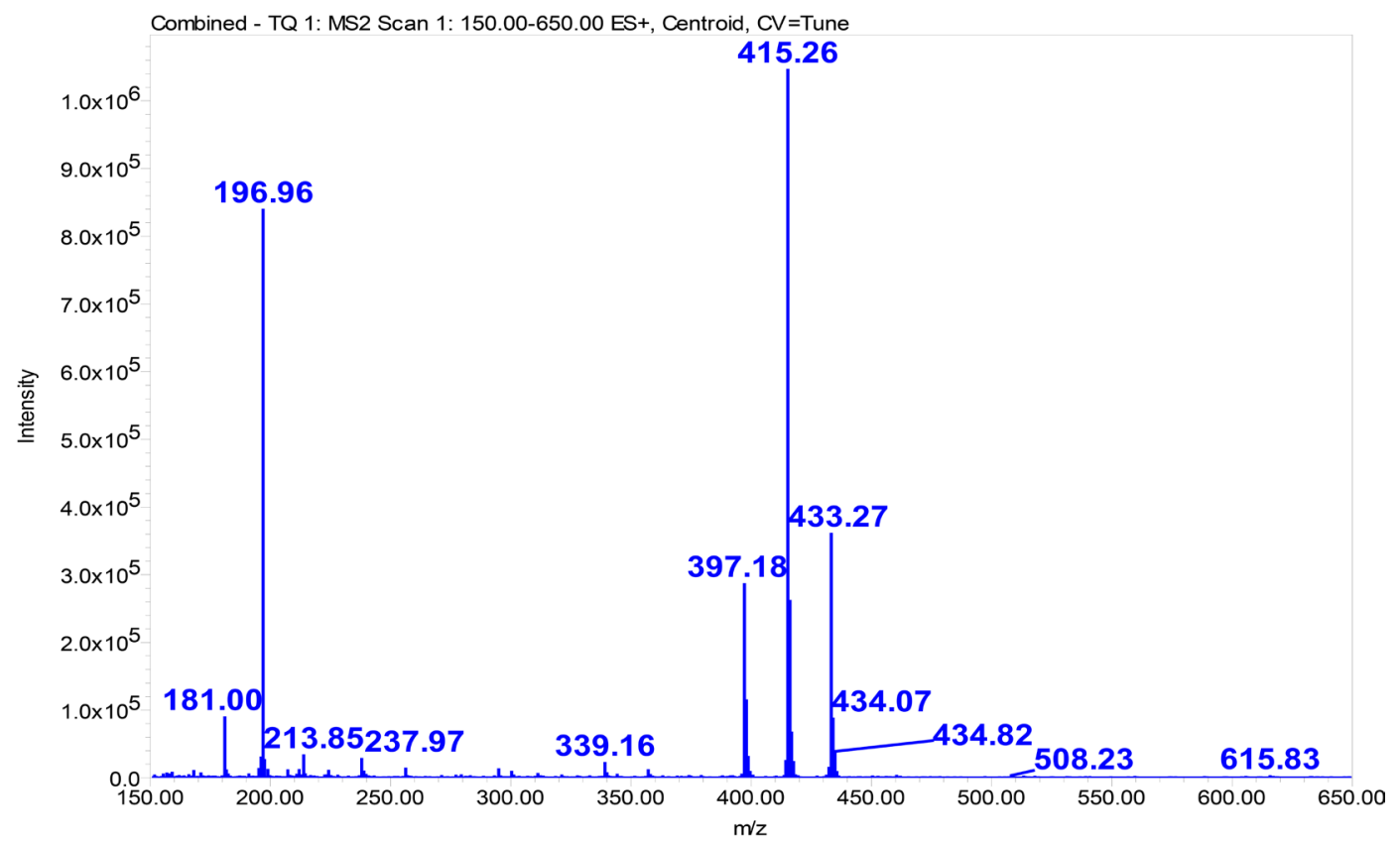

Figure 25. MS/MS Spectra of Desonide.

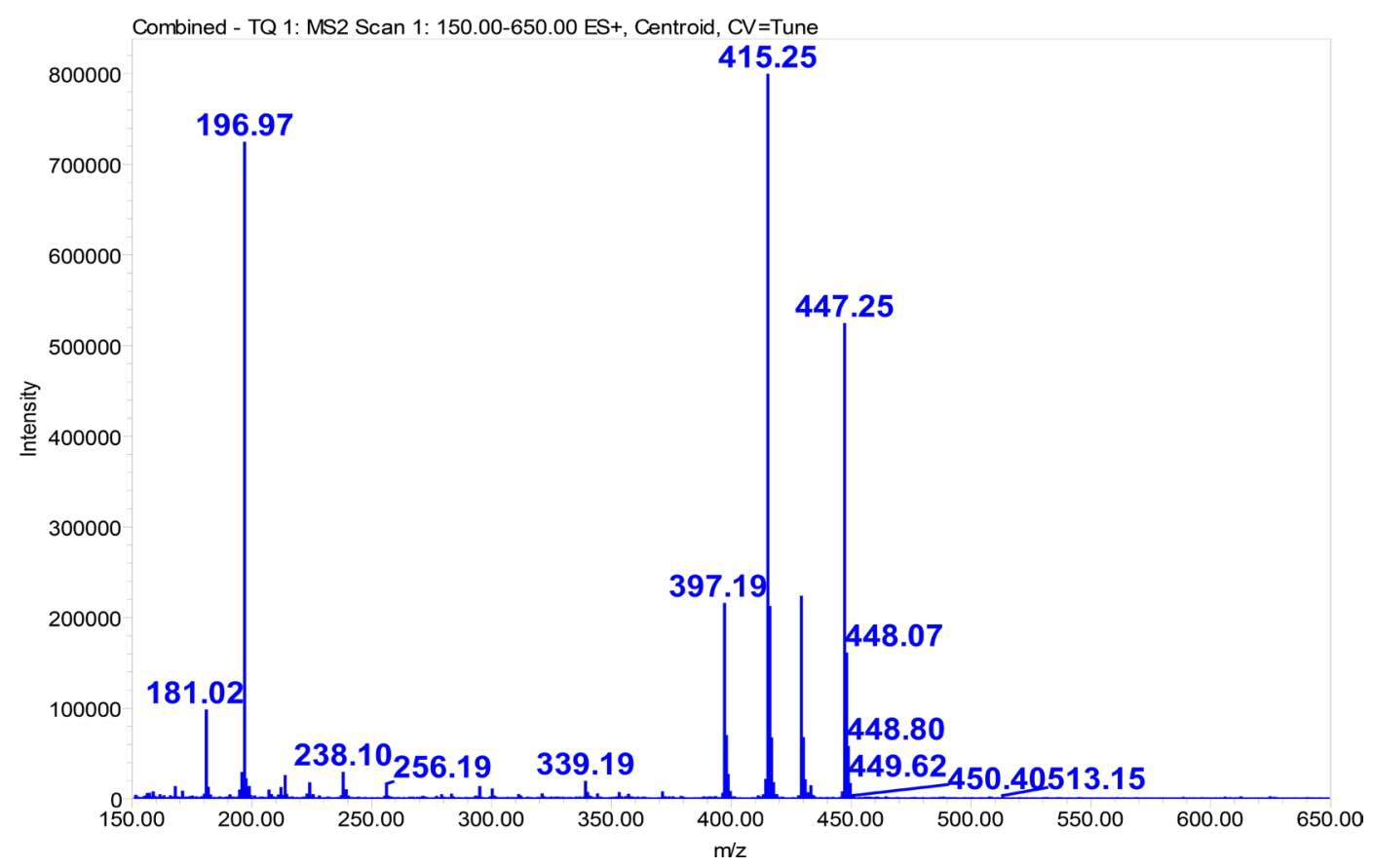

Figure 26. MS/MS spectra of Methoxy Desonide Impurity.

$\mathrm{pH})$, Hydrocortisone has proved to be unstable only on the basic side.

\section{Conclusion}

The degradants generated during the forced degradation and stability indicating studies of three corticosteroids in different topical formulations were investigated. The impurities were separated using a validated HPLC method and further elucidated using mass analysis by UPLC/MS-MS and NMR spectroscopic 
analyses. The mechanism of the formation of these impurities in corticosteroids was discussed in detail. The findings in the present study show that the choice of excipient grade, particle size and morphological characteristics of drug substance, emulsifying agent, solubilizing agent, presence of residual solvent in trace amount, water content in non-aqueous formulations are some of the critical parameters which could affect the stability of the drug product. The implementation of Quality By Design in every stage of the product life is encouraged to ensure both technical and regulatory success for the generic drug approval in the area of corticosteroids.

\section{Acknowledgements}

The authors wish to thank the management of Lupin Somerset for providing the infrastructure for the supporting of this research work. Cooperation from colleagues Product Development, Quality Control and Analytical Research \& Development of Lupin Somerset is appreciated.

\section{Conflicts of Interest}

The authors declare no conflicts of interest regarding the publication of this paper.

\section{References}

[1] Chen, B., Li, M., Lin, M., Tumambac, G. and Rustum, A. (2009) A Comparative Study of Enol Aldehyde Formation from Betamethasone, Dexamethasone, Beclomethasone and Related Compounds under Acidic and Alkaline Conditions. Steroids, 74, 30-41. https://doi.org/10.1016/j.steroids.2008.09.009

[2] Li, M., Chen, B., Lin, M., Chan, T.-M., Fu, X. and Rustum, A. (2007) A Variation of Mattox Rearrangement Mechanism under Alkaline Condition. Tetrahedron Letters, 48, 3901-3905. https://doi.org/10.1016/j.tetlet.2007.03.127

[3] Wasch, K.D., Brabander, H.D., Courtheyn, D. and Peteghem, C.V. (1998) Detection of Corticosteroids in Injection Sites and Cocktails by MSn. The Analyst, 123, 2415-2422. https://doi.org/10.1039/a804932g

[4] Arthur, K.E., Wolff, J.-C. and Carrier, D.J. (2004) Analysis of Betamethasone, Dexamethasone and Related Compounds by Liquid Chromatography/Electrospray Mass Spectrometry. Rapid Communications in Mass Spectrometry, 18, 678-684. https://doi.org/10.1002/rcm.1386

[5] Hotha, K.K., Reddy, S.P.K., Raju, V.K. and Ravindranath, L.K. (2013) Forced Degradation Studies: Practical Approach-Overview of Regulatory Guidance and Literature for the Drug Products and Drug Substances. International Research Journal of Pharmacy, 4, 78-85. https://doi.org/10.7897/2230-8407.04517

[6] International Conference on Harmonisation of Technical Requirements for Registration of Pharmaceuticals for Human Use, ICH Q 3 A (R) (2002) Impurities in New Drug Substances and Products.

[7] International Conference on Harmonisation of Technical Requirements for Registration of Pharmaceuticals for Human Use, Q 1 A (R2) (2000) Stability Testing of New Drug Substances and Products.

[8] International Conference on Harmonisation of Technical Requirements for Registration of Pharmaceuticals for Human Use, Q 2 (R1) (2005) Validation of Analytical 
Procedures: Text and Methodology.

[9] Li, M., Wang, X., Chen, B., Chan, T.-M. and Rustum, A. (2009) Forced Degradation of Betamethasone Sodium Phosphate under Solid State: Formation, Characterization, and Mechanistic Study of All Four 17,20-Diastereomers of Betamethasone 17-Deoxy-20-Hydroxy-21-Oic Acid. Journal of Pharmaceutical Sciences, 98, 894-904. https://doi.org/10.1002/jps.21477

[10] Antignac, J.-P., Le Bizec, B., Monteau, F. and André, F. (2002) Study of Natural and Artificial Corticosteroid Phase II Metabolites in Bovine Urine Using HPLC-MS/MS. Steroids, 67, 873-882. https://doi.org/10.1016/S0039-128X(02)00048-X

[11] Jänne, O., Vihko, R., Sjövall, J. and Sjövall, K. (1969) Determination of Steroid Mono- and Disulfates in Human Plasma. Clinica Chimica Acta, 23, 405-412. https://doi.org/10.1016/0009-8981(69)90340-4

[12] Axelson, M., Sahlberg, B.-L. and Sjövall, J. (1981) Analysis of Profiles of Conjugated Steroids in Urine by Ion-Exchange Separation and Gas Chromatography-Mass Spectrometry. Journal of Chromatography B Biomedical Sciences and Applications, 224, 355-370. https://doi.org/10.1016/S0378-4347(00)80208-X

[13] Fotsis, T., Adlercreutz, H., Järvenpää, P., Setchell, K.D.R., Axelson, M. and Sjövall, J. (1981) Group Separation of Steroid Conjugates by DEAE-Sephadex Anion Exchange Chromatography. Journal of Steroid Biochemistry, 14, 457-463. https://doi.org/10.1016/0022-4731(81)90357-5

[14] Hotha, K.K., Patel, T., Roychowdhury, S. and Subramanian, V. (2015) Identification, Synthesis, and Characterization of Unknown Impurity in the Famotidine Powder for Oral Suspension Due to Excipient Interaction by UPLC-MS/MS and NMR. Journal of Liquid Chromatography \& Related Technologies, 38, 977-985. https://doi.org/10.1080/10826076.2014.999201

[15] Hotha, K.K., Roychowdhury, S. and Subramanian, V. (2016) Drug-Excipient Interaction of Methylphenidate with Glycerin in Methylphenidate Oral Solution and Identification of Its Transesterification Products by UPLC-MS/MS. American Journal of Analytical Chemistry, 7, 151-164. https://doi.org/10.4236/ajac.2016.72013

[16] Hotha, K.K., Patel, T., Roychowdhury, S. and Subramanian, V. (2014) Development of Better-Quality Assay Method for the Citric Acid and Sodium Citrate in Ophthalmic/Oral Solutions and Their Application to Deformulation Studies. American Journal of Analytical Chemistry, 5, 1249-1260. https://doi.org/10.4236/ajac.2014.517131

[17] De Wasch, K., De Brabander, H.F., Van de Wiele, M., Vercammen, J., Courtheyn, D. and Impens, S. (2001) Differentiation between Dexamethasone and Betamethasone in a Mixture Using Multiple Mass Spectrometry. Journal of Chromatography $A$, 926, 79-86. https://doi.org/10.1016/S0021-9673(01)00744-0

[18] Schriks, M., van Leerdam, J.A., van der Linden, S.C., van der Burg, B., van Wezel, A.P. and de Voogt, P. (2010) High-Resolution Mass Spectrometric Identification and Quantification of Glucocorticoid Compounds in Various Wastewaters in the Netherlands. Environmental Science \& Technology, 44, 4766-4774. https://doi.org/10.1021/es100013x

[19] Hansen, J. and Bundgaard, H. (1980) Studies on the Stability of Corticosteroids V. The Degradation Pattern of Hydrocortisone in Aqueous Solution. International Journal of Pharmaceutics, 6, 307-319. https://doi.org/10.1016/0378-5173(80)90114-3

[20] Choi, M. (2000) Simultaneous Determination of Urinary Androgen Glucuronides by High Temperature Gas Chromatography-Mass Spectrometry with Selected Ion 
Monitoring. Steroids, 65, 54-59. https://doi.org/10.1016/S0039-128X(99)00082-3

[21] Spiegelhalder, B., Röhle, G., Sikmann, L. and Breuer, H. (1976) Mass-Spectrometry of Steroid Glucuronides. Journal of Steroid Biochemistry, 7, 749-756. https://doi.org/10.1016/0022-4731(76)90175-8

[22] Bowers, L.D. and Sanaullah (1996) Direct Measurement of Steroid Sulfate and Glucuronide Conjugates with High-Performance Liquid Chromatography-Mass Spectrometry. Journal of Chromatography B Biomedical Sciences and Applications, 687, 61-68. https://doi.org/10.1016/S0378-4347(96)00232-0

[23] Murray, S., Rendell, N.B. and Taylor, G.W. (1996) Microbore High-Performance Liquid Chromatography-Electrospray Ionisation Mass Spectrometry of Steroid Sulphates. Journal of Chromatography A, 738, 191-199.

https://doi.org/10.1016/0021-9673(96)00089-1

[24] Bean, K.A. and Henion, J.D. (1997) Direct Determination of Anabolic Steroid Conjugates in Human Urine by Combined High-Performance Liquid Chromatography and Tandem Mass Spectrometry. Journal of Chromatography B Biomedical Sciences and Applications, 690, 65-75. https://doi.org/10.1016/S0378-4347(96)00403-3

[25] Kuuranne, T., Vahermo, M., Leinonen, A. and Kostiainen, R. (2000) Electrospray and Atmospheric Pressure Chemical Ionization Tandem Mass Spectrometric Behavior of Eight Anabolic Steroid Glucuronides. Journal of the American Society for Mass Spectrometry, 11, 722-730. https://doi.org/10.1016/S1044-0305(00)00135-5

[26] Abend, A.M., Chung, L., Bibart, R.T., Brooks, M. and McCollum, D.G. (2004) Concerning the Stability of Benzyl Alcohol: Formation of Benzaldehyde Dibenzyl Acetal under Aerobic Conditions. Journal of Pharmaceutical and Biomedical Analysis, 34, 957-962. https://doi.org/10.1016/j.jpba.2003.11.007

[27] Li, M., Lin, M. and Rustum, A. (2008) Application of LC-MSn in Conjunction with Mechanism-Based Stress Studies in the Elucidation of Drug Impurity Structure: Rapid Identification of a Process Impurity in Betamethasone 17-Valerate Drug Substance. Journal of Pharmaceutical and Biomedical Analysis, 48, 1451-1456. https://doi.org/10.1016/j.jpba.2008.09.021

[28] Gentile, D.M., Tomlinson, E.S., Maggs, J.L., Park, B.K. and Back, D.J. (1996) Dexamethasone Metabolism by Human Liver in Vitro. Metabolite Identification and Inhibition of 6-Hydroxylation. Journal of Pharmacology and Experimental Therapeutics, 277, 105-112.

[29] Spangler, M. and Mularz, E. (2001) A Validated, Stability-Indicating Method for the Assay of Dexamethasone in Drug Substance and Drug Product Analyses, and the Assay of Preservatives in Drug Product. Chromatographia, 54, 329-334. https://doi.org/10.1007/BF02492678

[30] Chen, Q., Zielinski, D., Chen, J., Koski, A., Werst, D. and Nowak, S. (2008) A Validated, Stability-Indicating HPLC Method for the Determination of Dexamethasone Related Substances on Dexamethasone-Coated Drug-Eluting Stents. Journal of Pharmaceutical and Biomedical Analysis, 48, 732-738. https://doi.org/10.1016/j.jpba.2008.07.010

[31] Lewbart, M.L. and Mattox, V.R. (1963) Conversion of Steroid-17-Yl Glyoxals to Epimeric Glycolic Esters. The Journal of Organic Chemistry, 28, 1779-1786. https://doi.org/10.1021/jo01042a011

[32] Fauzee, A.F.B. and Walker, R.B. (2013) Forced Degradation Studies of Clobetasol 17-Propionate in Methanol, Propylene Glycol, as Bulk Drug and Cream Formulations by RP-HPLC: Liquid Chromatography. Journal of Separation Science, 36, 849-856. 
https://doi.org/10.1002/jssc.201200969

[33] Meng, L.-J. and Sjövall, J. (1997) Method for Combined Analysis of Profiles of Conjugated Progesterone Metabolites and Bile Acids in Serum and Urine of Pregnant Women. Journal of Chromatography B Biomedical Sciences and Applications, 688, 11-26. https://doi.org/10.1016/S0378-4347(97)88051-6 